\title{
In-plane lateral cyclic behaviour of lime-mortar and clay-brick masonry walls in dry and wet conditions
}

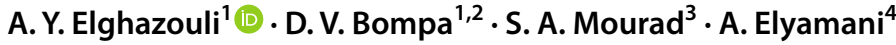

Received: 2 December 2020 / Accepted: 27 June 2021 / Published online: 16 July 2021

(c) The Author(s) 2021

\begin{abstract}
This paper presents an experimental investigation into the structural and material response of ambient-dry and wet clay-brick/lime-mortar masonry elements. In addition to cyclic tests on four large-scale masonry walls subjected to lateral in-plane displacement and coexisting compressive gravity load, the study also includes complementary tests on square masonry panels under diagonal compression and cylindrical masonry cores in compression. After describing the specimen details, wetting method and testing arrangements, the main results and observations are provided and discussed. The results obtained from fullfield digital image correlation measurements enable a detailed assessment of the material shear-compression strength envelope, and permit a direct comparison with the strength characteristics of structural walls. The full load-deformation behaviour of the large-scale walls is also evaluated, including their ductility and failure modes, and compared with the predictions of available assessment models. It is shown that moisture has a notable effect on the main material properties, including the shear and compression strengths, brick-mortar interaction parameters, and the elastic and shear moduli. The extent of the moisture effects is a function of the governing behaviour and material characteristics as well as the interaction between shear and precompression stresses, and can lead to a loss of more than a third of the stiffness and strength. For the large scale wall specimens subjected to lateral loading and co-existing compression, the wet-to-dry reduction was found to be up to $20 \%$ and $11 \%$ in terms of stiffness and lateral strength, respectively, whilst the ductility ratio diminished by up to $12 \%$. Overall, provided that the key moisture-dependent material properties are appropriately evaluated, it is shown that analytical assessment methods can be reliably adapted for predicting the response, in terms of the lateral stiffness, strength and overall load-deformation, for both dry and wet masonry walls.
\end{abstract}

Keywords Masonry walls · Lime mortar · Clay brick · Wet conditions · Cyclic loading · Lateral deformation $\cdot$ Diagonal cracking

A. Y. Elghazouli

a.elghazouli@imperial.ac.uk

Extended author information available on the last page of the article 


\section{List of notations}

\section{Latin uppercase}

$A_{c} \quad$ Cross-sectional area in compression

$A_{n} \quad$ Cross-sectional area of the member parallel to the bed joint

D Disc diameter

E Elastic modulus

$E_{m c} \quad$ Elastic modulus of the cylindrical core

I Area moment of inertia

$G \quad$ Shear stiffness

$K_{0} \quad$ Initial stiffness

$K_{\text {test }} \quad$ Test stiffness

$K_{\text {eff }} \quad$ Effective stiffness

$K_{e l} \quad$ Elastic stiffness

$N \quad$ Axial load

$P \quad$ Load

$P_{u} \quad$ Applied load at failure

$\varnothing \quad$ Diameter

$V_{1} \quad$ Shear force associated with shear sliding

$V_{2} \quad$ Shear force associated with stepped sliding

$V_{2, \text { lim }} \quad$ Shear force associated with shear-tensile cracking of bricks

$V_{3} \quad$ Shear force associated with compressive crushing

$V_{f} \quad$ Shear force associated with flexural failures

$V_{d} \quad$ Shear strength controlled by diagonal tensile cracking

$V_{d, \text { lim }} \quad$ Shear strength controlled by failure of brick units

$V_{s} \quad$ Shear force corresponding to shear sliding

$V_{s, l i m} \quad$ Limit shear force corresponding to shear sliding

$V_{\text {test }} \quad$ Test shear capacity

\section{Latin lowercase}

$b \quad$ Correction factor depending on the shear stress distribution in the panel and its aspect ratio

c Cohesion of singular brick-mortar interfaces

c' Cohesion of brick-mortar interfaces of masonry elements

d Member depth/width

d' $\quad$ Effective compression zone depth

$f_{b} \quad$ Brick unit compressive strength

$f_{b t} \quad$ Brick unit tensile strength

$f_{j} \quad$ Compressive strength of the mortar

$f_{t} \quad$ Diagonal tensile strength

$f_{m} \quad$ Estimated masonry compressive strength

$f_{m c} \quad$ Measured compressive strength on core samples

$f_{v} \quad$ Shear stress at failure

$f_{v 0} \quad$ Initial shear strength

$f_{v 0}$, Cohesion of brick-mortar interfaces of masonry elements

$f_{v 1} \quad$ Shear strength associated with shear sliding

$f_{v 2} \quad$ Shear strength associated with stepped sliding

$f_{v 2, \text { lim }} \quad$ Shear strength through shear-tensile cracking of bricks 
$f_{v 3} \quad$ Shear strength associated with compression crushing

$h \quad$ Height

$h_{b} \quad$ Height of the brick unit

$h_{g, i} \quad$ Gauge length

$l_{b} \quad$ Length of the brick unit

$l_{w}$, Distance between gauges

$n \quad$ Parameter for the number of perforations

$t \quad$ Thickness

$w_{a} \quad$ Water absorption ratio

\section{Greek letters}

$\alpha \quad$ Crack inclination angle

$\alpha_{K} \quad$ Boundary conditions parameter

$\varepsilon, \varepsilon_{1 i}, \varepsilon_{2 i} \quad$ Strains

$\varepsilon_{v} \quad$ Vertical strains

$\varepsilon_{h} \quad$ Horizontal strains

$\eta \quad$ Elastic modulus-to-compressive strength ratio

$\phi \quad$ Curvature distribution

$\varphi \quad$ Interlocking coefficient

$\gamma \quad$ Shear strain

$\mu \quad$ Slope of the Mohr-Coulomb criterion for singular brick-mortar interfaces

$\mu$ ' Slope of the Mohr-Coulomb criterion of masonry elements

$\mu_{\Delta} \quad$ Ultimate-to-yield drift ratio

$\sigma \quad$ Vertical stress, unless otherwise stated

$\sigma_{0} \quad$ Vertical stress in the compressed area of the member, unless otherwise stated

$\sigma_{n} \quad$ Vertical compressive stress to the bed joint from numerical analysis, averaged over the compressed zone

$\tau_{\max } \quad$ Peak shear stress from numerical analysis assessed at the same section as $\sigma_{\mathrm{n}}$

$\theta \quad$ Rotation

$\tau_{u} \quad$ Shear stress at failure

$\Delta \quad$ Drift

$\Delta_{\text {test }} \quad$ Test drift

$\Delta_{\text {peak }} \quad$ Drift at peak

$\Delta_{u} \quad$ Ultimate drifts

$\Delta_{u 2} \quad$ Second ultimate drift

$\Delta_{v, u} \quad$ Shear drift capacity

$\Delta_{s, u} \quad$ Ultimate sliding drift capacity

$\Delta_{s u 2} \quad$ Second sliding drift capacity

$\Delta_{d, u} \quad$ Ultimate diagonal tensile drift capacity

$\Delta_{d u 2} \quad$ Second diagonal tensile drift capacity

$\Delta_{u} \quad$ Yield drifts

\section{Introduction}

Historic masonry elements are rarely provided with adequate insulation systems to prevent capillary absorption, yet are often partly or fully submersed in groundwater (Hoła et al. 2017). Seasonal weather and hydrological variations also produce environmental wet-dry 
cycling which may have an influence on the performance of masonry (Giaccone et al. 2020; Lourenço et al. 2006; Mazzotti et al. 2014). A fundamental understanding and quantification of moisture effects on the mechanical properties of masonry materials and the structural performance of masonry elements are hence necessary.

The behaviour of masonry components under combined normal and shear actions can be largely characterised by three independent mechanisms: shear sliding, diagonal cracking, and compressive crushing. These mechanisms are typically assessed through material tests to define the limit strength domain of masonry in the form of shear-precompression diagrams (Malyszko 2004; Flores et al. 2013; Borri et al. 2011; Calderini et al. 2010). The interface brick-mortar bed joint response is characterised by a ratio of shear and precompression in a Mohr-Coulomb type representation, and is often obtained from small-scale triplet tests (Corinaldesi 2012; Pelà et al. 2017). It has been shown that the mortar-brick interface shear response is dependent on the moisture content, porosity, mortar strength, and conditioning type (Gentilini et al. 2012; Franzoni et al. 2014a). A recent comparative study on wet and dry triplets also indicated that the shear strength of wet triplets is, on average, about $20 \%$ lower than those in dry conditions for practical ranges of precompression (Bompa and Elghazouli 2020a).

The diagonal cracking mechanism, on the other hand, is characterised by splitting or stepped sliding along the mortar joints, with the ultimate condition depending on the properties and geometry of the brick and mortar as well as their interaction (Malyszko 2004; Stafford-Smith et al. 1970). Although various representative diagonal panel tests are reported in the literature, particularly for comparing strengthened and non-strengthened cases (Giaretton et al. 2018; Ismail et al. 2011; Koutas et al. 2014; Liu et al. 2015; Umair et al. 2015), such tests on wet conditions seem to be lacking to date. The third mechanism defining the shear-compression stress state is masonry crushing. Whilst there is general agreement that moisture reduces the compressive strength and elastic modulus of masonry, this varies with the mortar properties and brick unit porosity (Sathiparan and Rumeshkumar 2018; Franzoni et al. 2014b). For example, compressive strengths obtained from tests on prismatic samples and on cylindrical cores were found to be $13-18 \%$ lower for specimens with high moisture in comparison to those in dry conditions (Amade et al. 2004; Bompa and Elghazouli 2020b).

The ultimate conditions of structural masonry are typically evaluated using the shearcompression limit strength domain. Simplified assessment models and codified procedures for masonry components usually stipulate specific failure modes which are broadly classified into flexure and shear (BSI 2004; BSI 2005b; Elghazouli 2016). When flexure governs, a relatively ductile rocking-like mechanism occurs, and the element behaves like a rigid body with no or minimal diagonal cracking (Calvi et al. 1996; Tomaževič et al. 1996). Damage is typically concentrated at the edges of the supports, characterised by a toe crushing type behaviour. In contrast, shear failures occur through either diagonal cracking or sliding. The former is characterised by the development of inclined cracks whilst, in the latter, a portion of the wall slides horizontally along a bed joint under the action of lateral forces. Slender piers subjected to relatively low axial loads tend to overturn and exhibit rocking, whilst more stocky elements exhibit sliding due to a lower normal force along a horizontal joint (DeJong and Penna 2016). Relatively high levels of compressive axial load would impose axial restraints that limit flexural deformations and prevent sliding, hence promoting a diagonal cracking-controlled response. The failure mechanism is a direct result of the response type, yet the ultimate condition can be preceded by a flexure governed or a shear dominated behaviour (Wilding and Beyer 2017). 
The ductility and robustness of lateral-resisting masonry elements are of particular importance for structures subjected to seismic loading. To this end, previous studies have shown that the geometry, coupling level, and material properties, influence not only the strength but also the deformation capacity and cyclic degradation of masonry (Vasconcelos and Lourenço 2009; Asteris et al. 2014). For example, cyclic tests on ambient-dry unreinforced clay-brick/lime-mortar masonry squat walls with a heightto-depth ratio of 0.7 have indicated an essentially elastic response up to a lateral drift of about $0.05 \%$, limited deterioration up to $0.1 \%$, and an ultimate drift of around $0.6 \%$ (Lozincă et al. 2016). Comparative cyclic tests on dry low-strength mortar masonry also indicated a modification in failure mode from combined rocking-shear to rocking when the height-to-depth aspect ratio increased from 0.7 to 1.4 , representative of squat and slender elements, respectively (ElGawady et al. 2005). Other tests on small-scale dry historic masonry exhibited diagonal-cracking failures, reaching ultimate drifts below $0.4 \%$ (Capozucca 2011). The ultimate drift capacity of solid brick masonry with lime mortar, corresponding to the deformation at a lateral load of $80 \%$ of the peak resistance, was $0.83-1.21 \%$ in laboratory tests and $0.89-1.38 \%$ in in-situ tests (Kržan et al. 2015a).

Although experimental assessments on ambient-dry masonry walls representative of heritage structures have been carried out (Calvi et al. 1996; Tomaževič et al. 1996; Lozincă et al. 2016; ElGawady et al. 2005; Capozucca 2011; Kržan et al. 2015a; Magenes et al. 2010; Ismail and Ingham 2012), previous studies to investigate the lateral cyclic performance of wet large-scale masonry are limited. The compressive and tensile mechanical properties of wet brick lime mortar masonry subjected to in-situ push-only cyclic loading were reported to be $30 \%$ and $36 \%$ lower, respectively, than those of corresponding members in dry conditions (Kržan et al. 2015b). These reductions were attributed to the very low modulus of elasticity of wet masonry compared to its dry counterpart, with the mortar exhibiting stiffness equal to that of saturated sand. Lateral push-only cyclic loading tests on masonry infilled timber frames indicated a reduction in stiffness and strength up to $75 \%$ and $36 \%$ respectively, as well as a change in failure mode from shear (by sliding along the horizontal joint) to diagonal compression, due to exposure to moisture resulting from flood and wind-driven rain (Stephenson and D'Ayala 2019). Although the influence of moisture on the diagonal cracking response was examined in push-only lateral load tests, the influence of load reversals combined with moisture on clay brick lime mortar masonry has not been investigated. These aspects of behaviour are particularly important for assessing the structural robustness of heritage structures. Such masonry structures are typically also not specifically designed for resisting lateral seismic loading. This paper therefore presents an experimental investigation into the material and structural response of ambient-dry and wet masonry elements consisting of fired clay brick and hydraulic lime mortar, which are used in many historic structures. The properties of the fired-clay bricks and lime-mortar materials were selected to resemble those of masonry components investigated in a wider research programme on the management and conservation of heritage masonry structures in Historic Cairo (Elghazouli et al. 2018). The experimental programme from this paper includes tests on square panels under diagonal compression, cylindrical cores in compression, as well as large-scale walls subjected to gravity load and lateral cyclic displacements. In addition to providing information for future validation of detailed nonlinear cyclic numerical simulations, the results enable the assessment of the material shear-compression strength envelopes as well as the adequacy 
of available analytical models in terms of stiffness, strength and load-deformation response.

\section{Experimental programme}

\subsection{Material properties and mix designs}

Commercial fired clay facing solid bricks with measured sizes of $229 \times 110 \times 66 \mathrm{~mm}$ were used for the construction of all specimens (Egernsund Tegl et al. 2019). The nominal compressive strength for elements tested parallel to bed face is provided by the manufacturer as $13 \mathrm{MPa}$ (BSI 2011; BSI 1999a; Zhou et al. 2008). The measured average compressive strength of brick units parallel to the testing bed, obtained from a minimum of three tests, was about $15.5 \mathrm{MPa}$ in both dry and wet conditions, with the latter corresponding to full submersion in water for $48 \mathrm{~h}$. From readily available materials, this type of fired-clay bricks has the closest physical and mechanical properties to those from the Mausoleum of Fatima Khatun (Umm al-Salih) built in the thirteenth century in Cairo, which is assessed in the project (Elghazouli et al. 2018). Site surveys indicated that: (i) 'red' bricks (used for the foundation) have a compressive strength $\left(\mathrm{f}_{\mathrm{b}}\right)$ of about $5.2 \mathrm{MPa}$ and water absorption $\mathrm{w}_{\mathrm{a}}=27.5 \%$, (ii) 'light brown' bricks have an $\mathrm{f}_{\mathrm{b}}=14.7 \mathrm{MPa}$ and $\mathrm{w}_{\mathrm{a}}=18.1 \%$ and (iii) 'dark brown' bricks have an $\mathrm{f}_{\mathrm{b}}=22.7 \mathrm{MPa}$ and $\mathrm{w}_{\mathrm{a}}=13.4 \%$ (Elghazouli et al. 2018). The characteristics of the selected fired-clay bricks are hence within the range of those from the site survey, typically found in such heritage masonry (Zhou et al. 2008), and can be used for comparative assessments and structural repair studies.

The freeze/thaw resistance category of the selected fired-clay bricks, as specified by the manufacturer, is F2 and corresponds to severe exposure conditions. The active water-soluble salts, related to those naturally occurring in clays used for brick manufacturing, is classified as content category S0, indicating no requirements for salts content. Additionally, the moisture content of both conditioning cases for bricks was assessed. The ambient-dry samples and those submersed in tap water for a minimum of $48 \mathrm{~h}$, were dried in an oven for $6 \mathrm{~h}$ at $60{ }^{\circ} \mathrm{C}$ and another for $18 \mathrm{~h}$ at $105^{\circ} \mathrm{C}$ until the sample mass was relatively constant. The moisture content of ambient-dry bricks was $0.07 \%$ by weight (wt.\%), and $10.5 \mathrm{wt} . \%$ for those submersed in water. These values are in close agreement to those provided by the manufacturer (water absorption $\mathrm{w}_{\mathrm{a}}<10 \%$ (Egernsund Tegl et al. 2019)).

Mortars incorporating natural hydraulic lime (NHL) with a binder-to-aggregate ratio of $1: 3$ were selected for the study as these are typically used for conservation works. An eminently hydraulic binder (NHL5) (Bompa and Elghazouli 2021; BSI 2010), with a specific gravity of 2.70 was used in the mortars. These are singular binders which combine hydraulic with air setting, obtained by carbonation with atmospheric $\mathrm{CO}_{2}$. The free lime $\mathrm{Ca}(\mathrm{OH})_{2}$ is above 15\%, whilst the sulphates content is below 2\% (Secil Argamassas 2019). Mortars with a consistency of 180-200 mm were prepared in the proportions given below, in two batches (BSI 1999c) with different constituents, for comparison purposes in terms of workability and strength. In both cases, for one part of NHL5 lime, 3.25 parts of soft sand were used. In the first batch (A) about 1.20 parts of tap water were added, whilst in the second batch (B) 0.75 parts of tap water and 0.014 parts of polycarboxylate admixtures were mixed, although the latter are not commonly used in lime mortars. The specific gravity of the sand, typically used for bricklaying and pointing applications (BSI 2012, 2013), was 2.65 and its water absorption was around $5 \%$. 
The mix constituents were pre-batched in $15 \mathrm{~L}$ buckets and mixed until becoming homogenous using a hand-held electric paddle mixer (BSI 1999b). Samples of fresh mortar were taken selectively, covered with a plastic sheet and removed from moulds after five days. These were then kept near the masonry specimens in laboratory conditions. Compressive strengths were determined from compression tests on ambient-dry and wet cubes $(50 \times 50 \times 50 \mathrm{~mm})($ BSI 1999c). A minimum of 5 samples were tested for each masonry specimen. They had the same conditioning as the corresponding masonry element. After carefully measuring all dimensions using a digital calliper, the specimens were tested in compression at a displacement rate of $0.25 \mathrm{~mm} / \mathrm{min}$.

The resulting strengths of the mortars in ambient-dry conditions were between 1.29 and 2.24 MPa for Batch A samples, whilst for Batch B samples the strengths were between 3.47 and 5.06 $\mathrm{MPa}$. The compressive strengths in wet conditions were between 0.58 and 1.19 MPa for Batch A samples, and these were between 1.62 and $2.37 \mathrm{MPa}$ for samples from Batch B. An average reduction in elastic modulus in the range of $50 \%$ was typically observed due to moisture. Additionally, the moisture content of both conditioning cases for NHL mortar samples was assessed following the same procedure as for the bricks. The moisture content of the lime mortars was $2.54 \%$ by weight (wt. $\%$ ) for ambient-dry samples and 10.80 (wt.\%) for those submersed in water.

As mentioned before, it should be noted that the materials were selected to represent the range of mechanical and physical properties of the bricks and mortars as those from prototype structures built in the thirteenth century in Cairo (Mamluk period). Based on assessments of mortar samples extracted from the original structures (Sherif and Elghazouli 2020), the hydraulic lime and sands constituents described above were chosen to match as closely as possible those from the original structures. To this end, the two mortar batches were selected to represent the mechanical strength ranges suggested in the literature. Based on available studies, compressive strength ranges for historic masonry mortar typical of the Mamluk period in thirteenth century Cairo and similar mortars indicated a wide strength range of 0.63-5.67 MPa (Thomas 2004; Maravelaki-Kalaitzaki et al. 2005; Drougkas et al. 2016), and even reaching higher values in some cases (Dorji et al. 2021). In general, however, it should be noted that Batch A mortar would be more representative of typical 'historic' masonry, whilst Batch B would represent higher values reported in the literature for the specific forms considered in this study.

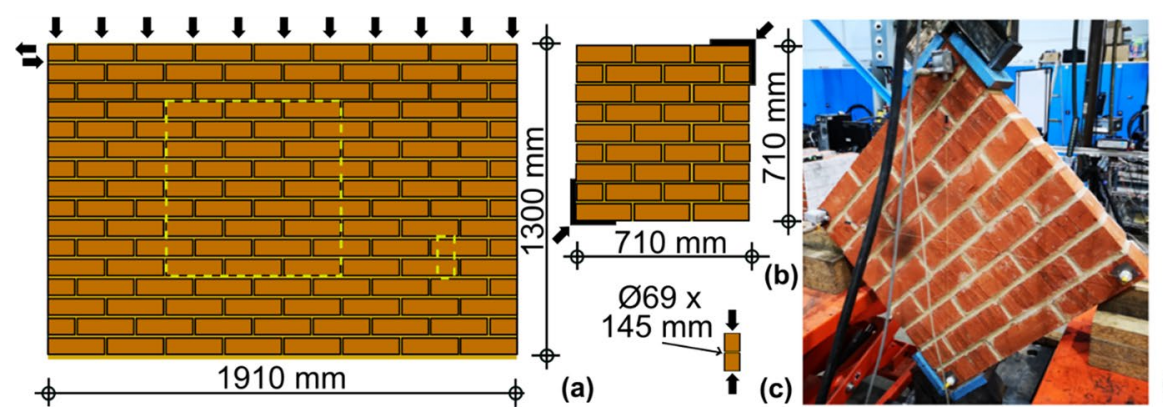

(d)

Fig. 1 Specimen details: a large-scale walls, b diagonal panels, $\mathbf{c}$ cylindrical cores, $\mathbf{d}$ view of the diagonal panels 


\subsection{Specimen details}

\subsubsection{Small scale tests}

In addition to the large-scale walls of width $\times$ height $\times$ thickness $(b \times h \times t)=1910 \times$ $1300 \times 110 \mathrm{~mm}$, which were tested under combined loading (as illustrated in Fig. 1a and described in the following section), small scale tests on both wet and air-dry specimens were also carried out in order to assess the homogenised masonry properties. The small-scale tests included: (i) diagonal tests on single leaf square masonry panels of $\mathrm{b} \times \mathrm{h} \times \mathrm{t}=710 \times 710 \times 110 \mathrm{~mm}$ (Fig. 1b,d), and (ii) compression tests on cylindrical masonry cores of $69 \mathrm{~mm}$ diameter and $145 \mathrm{~mm}$ length, extracted after testing from undamaged areas of the diagonal panels or large-scale walls (Fig. 1c). The specimen reference adopts the format $\mathrm{D} X-Y z$, where $\mathrm{D}$ stands for diagonal panel, $X$ indicates the specimen batch (A or B), $Y$ represents the conditioning (D for air-dry or $\mathrm{W}$ for wet) and $\mathrm{z}$ represents the specimen sequence $(1,2,3$, etc.).

As noted above, the cylindrical masonry cores were extracted after testing from undamaged areas of the diagonal panels or large-scale walls. After testing, areas without visible damage were marked, and the strain condition during testing was assessed using detailed digital image correlation (DIC) measurements. Cores were only extracted from areas in which strain values were well below cracking or crushing. Also, out of 5-15 cores extracted per wall, only 3-5 cores which had no damage due to coring, were tested. Despite not being a standardised method, coring is often used to assess the mechanical properties of existing masonry structures (e.g. Pelà et al. 2018; Dorji et al. 2021), and the results obtained can be correlated with results from standardised tests. The results from the cores tested herein, and discussed in subsequent sections, were also in line with those obtained from a complementary investigation carried out by the authors on the compression properties of fired clay bricks and lime mortar masonry, in which cylindrical cores were extracted from untested wallettes (Bompa and Elghazouli 2020b). Nonetheless, it should still be noted that such non-standardised methods can only be considered to provide informative results and that standardised tests should be carried out where possible.

The panels for diagonal testing (Specimens DA-Dz, DA-Wz, DB-Dz and DB-Wz), as depicted in Fig. 1b,d, had both horizontal and vertical lime mortar joints with an average thickness of $9 \pm 1.5 \mathrm{~mm}$. After the last course of bricks was laid, the specimens were kept in laboratory conditions. Plastic sheets were used to cover the specimens at early curing and they were tested at an age of 30-35 days. Prior to testing, the wet specimens were submersed $3 / 5$ of depth in water and were sprinkled with a hose from the top. This procedure ensured even moisture distribution across the specimen. After testing, the wall was dismantled, and samples were extracted to assess the moisture content. After each brick and mortar joints were weighed, all components were dried in an oven for $6 \mathrm{~h}$ at $60{ }^{\circ} \mathrm{C}$ and for at least $18 \mathrm{~h}$ at $105^{\circ} \mathrm{C}$ until the sample mass became largely constant. The moisture distribution results indicated that the same moisture content of $10.7 \% \pm 0.2$ wt was consistently obtained in all nine brick courses. The moisture content was therefore shown to be evenly distributed across the specimens.

To assess the compressive strength of the masonry, cylinders made of two vertical brick cores, with a mortar joint of about $10 \mathrm{~mm}$ in between, were extracted from the diagonal panels and the large walls (Fig. 1c). As noted above, the cylinders had a diameter $\mathrm{d}=69 \mathrm{~mm}$ and height of around $\mathrm{h}=145 \mathrm{~mm}$, representing an aspect ratio $\mathrm{h} / \mathrm{d} \approx 2.10$. Such geometries $(\mathrm{h} / \mathrm{d} \geq 2.0)$ are required to ensure a uniaxial stress state at mid-height of 
the specimen and to obtain the material strength rather than the response of the specimen (Bompa and Elghazouli 2020b; Oliveira et al. 2006). To ensure a moisture content which is similar to that of the large walls and diagonal panels, the cylinders were submersed for $48 \mathrm{~h}$ in water. Close inspection of the data obtained from submersing these elements, as well as their constituent components (bricks, mortar samples and bricks with mortar joints), in water for a period of $24 \mathrm{~h}$, indicated that after $3 \mathrm{~h}$ the masonry specimens had a relatively constant weight. Moreover, the moisture content assessment, following the procedure described above for the diagonal panels, showed that the moisture was between 10-11\%wt. It is hence considered that all wet conditioning procedures employed had the same effect on the various masonry elements examined in this study regardless of their size.

\subsubsection{Large walls under combined loading}

Single leaf masonry walls of $1910 \mathrm{~mm}$ length, $1300 \mathrm{~mm}$ height and $110 \mathrm{~mm}$ width were built using the materials described above in Sect. 2.1. As noted before, the aim of this study is to investigate the response of masonry components under wet and dry conditions. From the set of four large-scale specimens tested under lateral cyclic loading, two were in air-dry and two were in wet conditions. All walls were subjected to an axial load of $223.3 \pm 3.5 \mathrm{kN}$ corresponding to a vertical stress of $1.06 \pm 0.02 \mathrm{MPa}$ (Table 4). The specimen reference adopts the format $\mathrm{W} X-Y$, where $\mathrm{W}$ stands for wall, $X$ represents the specimen batch: (A or B), and $Y$ represents the conditioning (D for air-dry or $\mathrm{W}$ for wet). For example, WA-D is the first test on ambient-dry walls.

The masonry walls were constructed on $25 \mathrm{~mm}$ thick mild steel plates, prepared with threaded holes (for M20 bolts) for connection to the rig support beam and to facilitate cranage. To ensure appropriate surface roughness between the support steel plate and the masonry wall, the plate was ground using an angle grinder and prepared with a layer of river sand with sizes up to $5 \mathrm{~mm}$. After grinding the plate and cleaning it with acetone, a two-component epoxy bonding agent was poured on the plate. While the epoxy was still fresh, the sand was spread over. After $24 \mathrm{~h}$, excess sand was removed by air blasting.

Stretcher/running bond was used to construct the 16 course high walls. The first course included 8 full bricks per length, whilst each second consecutive course included 7 full bricks and 2 half bricks. To achieve the desired specimen height, the mortar joint thickness was in the range of $8-10 \mathrm{~mm}$. The bricks were laid as received from the manufacturer without any conditioning or soaking in water prior to placing the mortar. The bricklaying procedure started with a mortar layer on the hardened sand-epoxy layer. After the last course of bricks was placed, the walls were surface wetted and covered with plastic sheets to ensure appropriate hydration. Three days before testing, the top transfer beam was placed on the wall and tied to the bottom support steel plate by means of six $\varnothing 20 \mathrm{~mm}$ threaded ties (see Fig. 2a).

To ensure similar bond conditions at the wall top and bottom, the bottom surface of the transfer beam was also prepared following the procedure applied to the support steel plate. Prior to placing the top transfer beam, a 5-10 mm high strength cement mortar layer was laid on at the top of the masonry wall. A high strength cement mortar was required for the wall-to-transfer beam mortar layer in order to match the strength of lime mortars on the day of testing. The wall was prestressed vertically using threaded ties and then transported by crane to the test rig (Fig. 2a). Prestressing ensured a slight compression state to the wall while being transported. The plate-wall-beam assembly was then placed on the rig support plate and tied using $6 \times \varnothing 20 \mathrm{~mm}$ bars each side of the wall. After the wall was tied to the 

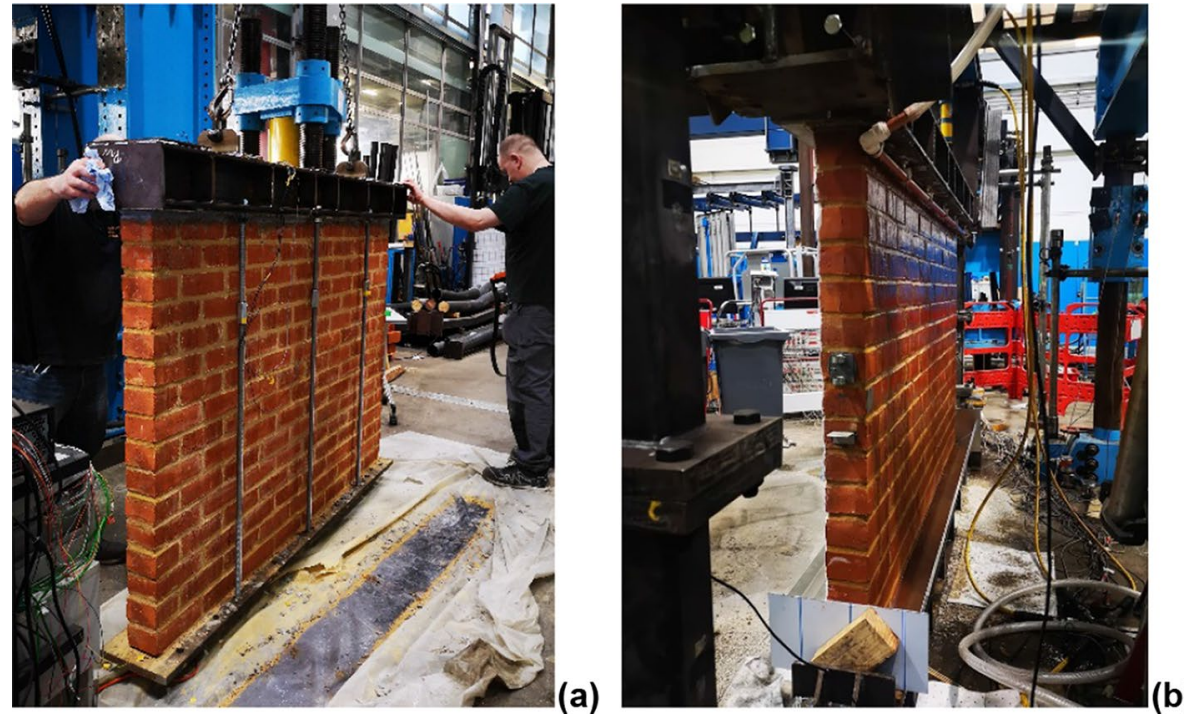

Fig. 2 Large-scale wall specimen preparation details: a transportation, $\mathbf{b}$ wetting system

bottom beam and secured for out-of-plane movement, the prestressing ties were removed, and the mechanical instrumentation was installed.

For the walls tested under wet conditions, the same preparation procedure was followed. To enable wetting through capillary absorption, after the specimens were placed in the testing rig and the prestressing ties were removed, a water tank was built in-place which was connected to the first course of bricks (Fig. 2b). The water tank consisted of $1.0 \mathrm{~mm}$ aluminium sheets placed around the perimeter of the wall and tied by means of structural silicone. Tap water was poured into the tank after the silicone reached its setting time. The rising damp resulting from capillary absorption was observed visually and marked on the wall. In addition to the water tank, a pipe/sprinkler system mounted at the top of the wall was manufactured and was used to accelerate the wetting process.

To obtain the moisture content of the tested wall and enable direct comparisons with the moisture content of constituent materials as well as the small scale tests described above, twelve samples from the each wet wall (WA-W and WB-W) were taken after testing. The samples were weighed before and after being placed in an oven for $24 \mathrm{~h}$ at $105^{\circ} \mathrm{C}$. The average moisture content was $11.1 \%$ by weight which is very similar to the values obtained for brick units and mortar independently. The standard deviation was $0.34 \%$, indicating that the moisture was evenly spread throughout the wall.

\subsection{Testing arrangements}

\subsubsection{Test set-ups and loading procedures}

The tests on diagonal panels were carried out in a rig which included a main loading transfer frame with a $1000 \mathrm{kN}$ Instron actuator and a connected load cell. As shown in Fig. 3a, the specimens were positioned and loaded through V-shaped supports. The load was 
Fig. 3 Testing arrangement of small-scale tests: a diagonal panels, $\mathbf{b}$ cores in compression

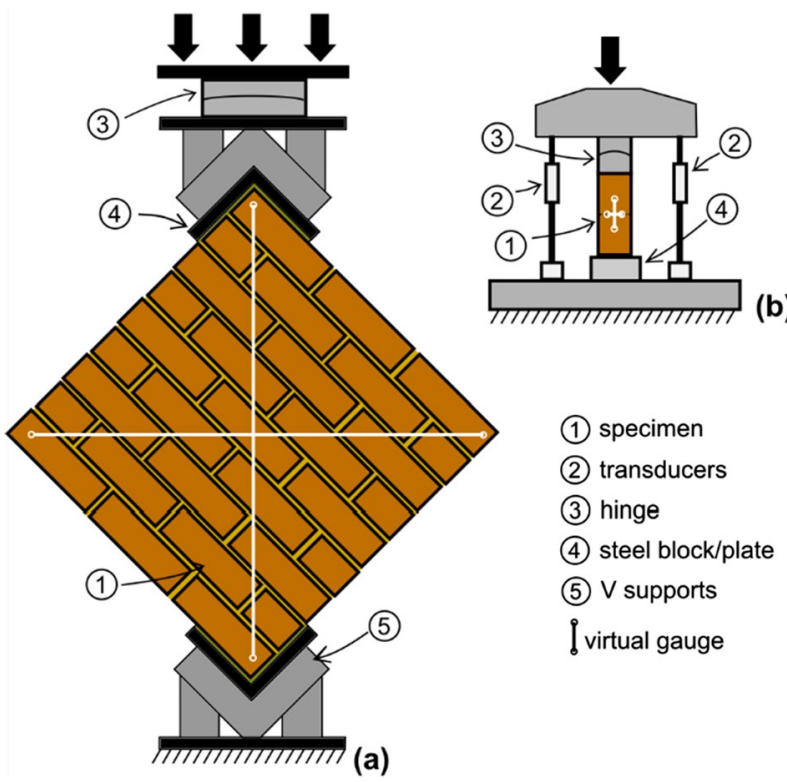

applied from the actuator to the top support by means of a hinge. To ensure uniform contact between the loading/support plates and the specimen, a thin timber panel was used. On the other hand, for testing the cylinders in compression, a stiff four-post hydraulic servocontrolled machine with a capacity of $750 \mathrm{kN}$ was used. The cores were tested using the arrangement shown in Fig. 3b. In all cases, external transducers were used for secondary measurements alongside the displacement recordings provided by the machine, coupled with detailed data from a Digital Image Correlation (DIC) system, as described below.

The testing arrangement for the large-scale wall specimens is shown schematically in Fig. 4a. The rig was designed to enable realistic experimental assessment of the ultimate behaviour of large-scale members subjected to lateral cyclic displacements and co-existing axial loading. The specimens were directly supported by a $25 \mathrm{~mm}$ thick plate and connected by means of prestressed $\varnothing 20 \mathrm{~mm}$ bolts to a supporting steel beam. The latter was connected to the strong floor by means of $4 \times \varnothing 33 \mathrm{~mm}$ pre-stressing ties to avoid sliding and overturning under lateral loads. At the top of the wall, three $120 \mathrm{kN}$ Enerpac actuators were connected to a steel loading beam and were used to apply the gravity load by means of unidirectional hinges to the specimen through a transfer steel beam. The loads from the vertical actuators were monitored throughout the test to ensure that the axial force applied to the wall was largely constant (within $\pm 2 \%$ of the initial applied load). The loading, transfer and support beams were made of back-to-back channel sections. The loading beam was connected to the support beam by means of two pin-ended square $80 \times 8 \mathrm{~mm}$ hollow section ties.

For the application of the lateral loading, another $250 \mathrm{kN}$ Instron actuator was placed horizontally and connected to the reaction frame. The axial gravity loads and the lateral displacements were controlled by two different control units. This testing arrangement allowed the top transfer beam to rotate, representing the case of a cantilever masonry wall. Loads and displacements were recorded throughout the entire testing procedure at a frequency of $1 \mathrm{~Hz}$. For comparison purposes, besides the load cells located at each actuator, 

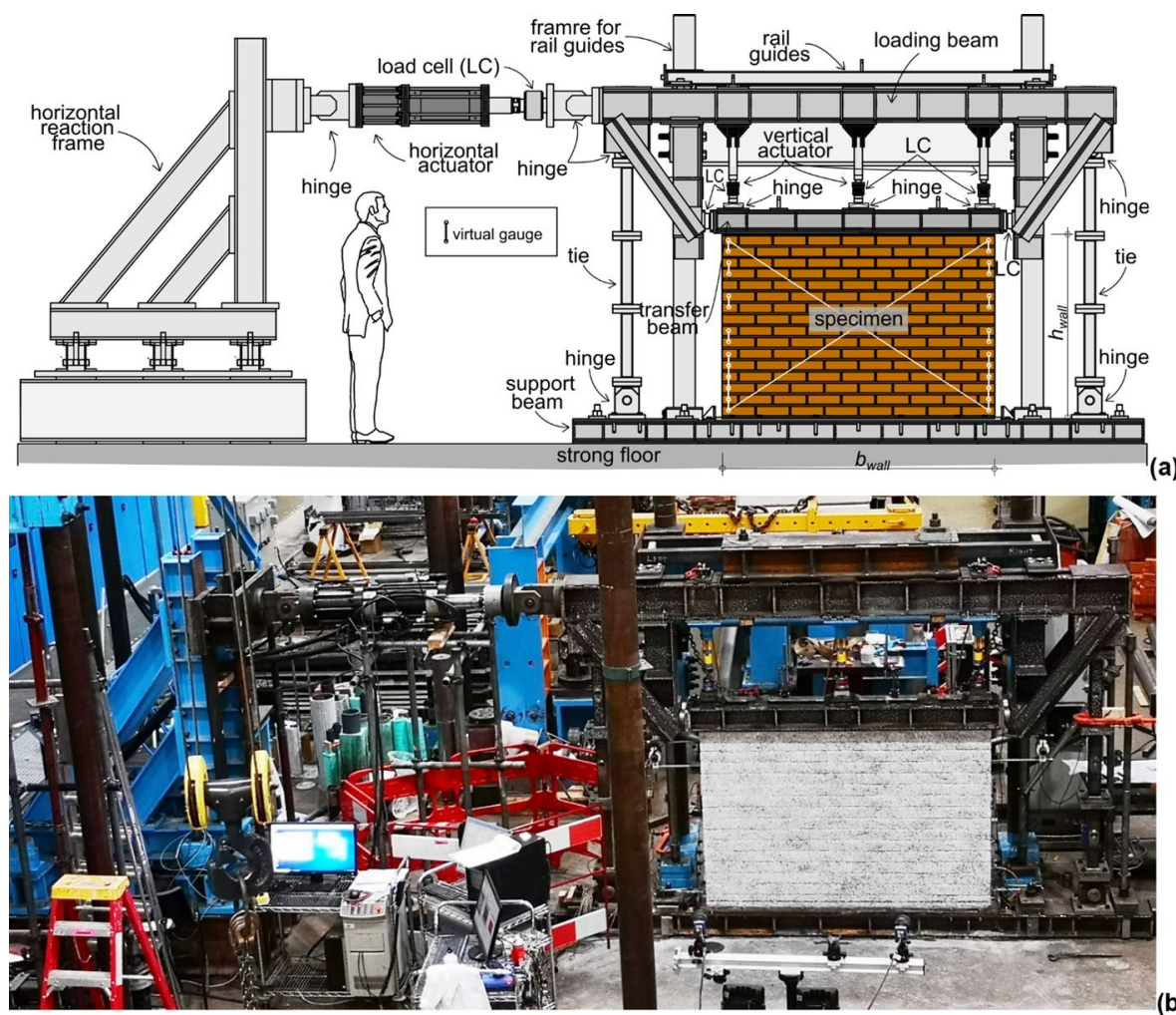

Fig. 4 a Schemtic representation of the large-scale walls testing arrangement, b General view of test rig

two load cells of $100 \mathrm{kN}$ were placed between the diagonal transfer struts and the transfer beam. A system of steel elements was manufactured to provide out-of-plane stability to the masonry specimen. Two braced cantilevers made of L100 $\times 200$ sections, with vertical steel rods of $\varnothing 50 \mathrm{~mm}$ diameter and provided with a double row of steel wheel bearings $(44 \times 2.5 \times 37 \mathrm{~mm})$, were connected to a stiff frame. The vertical steel rods and wheel bearings were inserted between the back-to-back channel sections of the loading beam. With a clearance of around $1.0 \mathrm{~mm}$, the system ensured restraint against any out-of-plane movement of the load transfer frame (loading and support beam, as well as the two side ties) and the specimen (Fig. 4b).

The large wall specimens were tested in an upright position as shown in Fig. 4, with the vertical load applied to the member through the transfer beam. After the application of the constant vertical load, corresponding to an axial load of $223.3 \pm 3.5 \mathrm{kN}$ corresponding to a vertical stress of $1.06 \pm 0.02 \mathrm{MPa}$ (Table 4 ), the lateral deformations were applied based on a pre-defined quasi-static cyclic history. A set of three cycles were applied for each deformation level, corresponding to a drift of $0.025,0.050,0.075,0.10,0.15,0.20,0.25,0.30$, $0.35,0.40,0.50,0.80,1.0,1.25,1.50(\%)$. The displacement rate and loading procedure were chosen based on recommendations available in the literature (Petry and Beyer 2015a; Magenes et al. 2008). Lower displacement rates were applied at low drift levels to capture cracking and spalling of mortar and bricks, and this was increased gradually with the drift ratio. 


\subsubsection{Instrumentation details}

For the diagonal panel tests, besides the machine load and displacement, 2 string pots placed along the two diagonals of the panel, were used. On the other hand, vertical transducers were used to obtain axial deformation of the cylinders tested in compression. The instrumentation of the large-scale walls, apart from the load cells and displacement transducers incorporated within the horizontal and vertical actuators, included 12 additional displacement transducers, 4 string pots of which 2 measured diagonal shear displacement and 2 were inclinometers.

A Digital Image Correlation (DIC) system was also employed to record detailed local deformations and strains within the surface of all specimens: large walls, diagonal panels, and cylindrical cores. The DIC system consists of two light-weight CMOS cameras with a USB 3.0 interface for distances up to $25 \mathrm{~m}$. The high sensitivity cameras have a resolution of $2.3 \mathrm{Megapixel}$ at $100 \mathrm{~Hz}$ frame rate. These are connected to a controller which also acts as a data acquisition system. As part of the preparation process, the specimens were firstly painted in white, and then carefully speckled with $0.5-2.0 \mathrm{~mm}$ black dots to create a highcontrast black-white pattern. The size of the black dots depended on the size of the specimen and distance between the cameras and speckled surface.

Prior to testing, a DIC calibration procedure was undertaken by adjusting iteratively the aperture, ambient lighting, and camera focus, while taking photos of a calibration plate adjacent to the specimen face. This was required to allow the post-processing software to determine the distance between the cameras and the specimen and, subsequently, to compute the surface strain vector fields. A data recording frequency of $0.2 \mathrm{~Hz}$ was chosen to acquire a sufficiently large pool of data to minimise possible scatter. After testing, the DIC data were further processed to obtain deformation vector fields. From these, surface strains or deformations were obtained from assigned virtual gauges with various lengths depending on the required measurement.

\section{Test results and observations}

\subsection{Small scale specimens}

This section describes the test results of the small-scale specimens illustrated in Fig. 3, to assess the main mechanical properties of lime-mortar/clay-brick masonry. These include

Fig. 5 Shear stress, shear strain response of diagonal panels: a DA-D and DA-W, b DB-D and DB-W
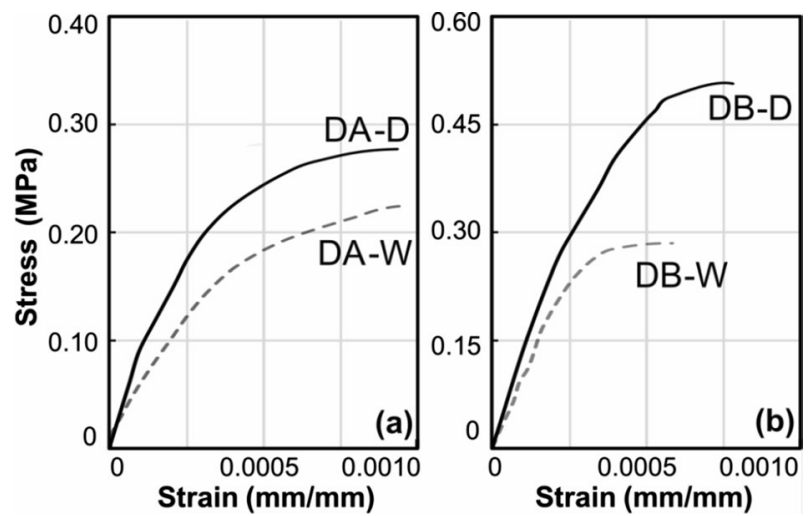
Fig. 6 Failure patterns of selected diagonal panels: a DA-D1, b DA-W3, c DB-D2, d DB-W1

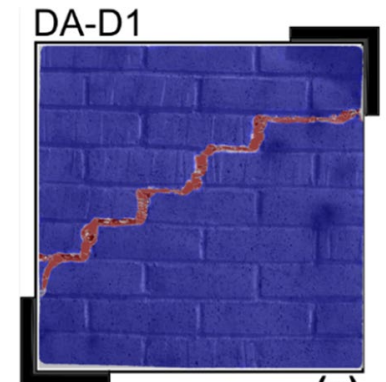

(a)

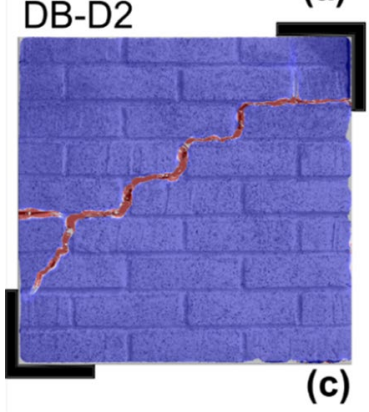

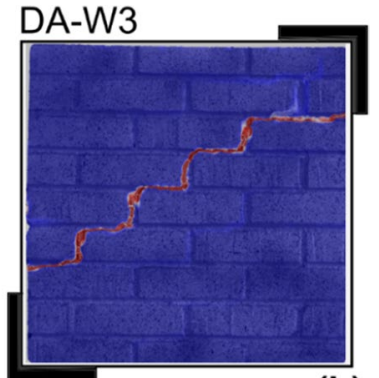

(b)

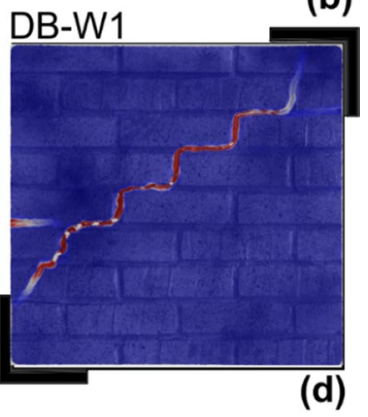

the tests on the square panels under diagonal compression as well as the cylindrical cores in compression. As noted in Sect. 2.2, diagonal compression tests were carried out on the masonry panels to obtain the diagonal tensile strength. Figure 5 depicts the average stress-strain behaviour obtained from the tested panels, separately for Batches A and B, whilst Fig. 6 illustrates the typical crack patterns at failure for selected elements. In the diagonal panel tests, the ultimate condition occurs when the principal tensile stresses perpendicular to the compressed strut reaches the maximum tensile strength of the masonry. After the tensile strength is reached, cracking occurs and, with the increase in compression displacement, leads to crack widening and panel failure (Calderini et al. 2010). Failure generally occurs due to bond failure between the brick unit and the mortar in the joints ( $\mathrm{Li}$ et al. 2005).

The principles of ASTM E519-02, which consider a pure shear stress state (i.e. the principal stresses are equal and of opposite signs, and the load direction angle is at $45^{\circ}$ ), were used as a basis to interpret the results from the diagonal panel tests (Calderini et al. 2010; ASTM 2002). Considering these assumptions, for a panel with the same depth/width and with height $h$ and thickness $t$, the shear stress at failure $\tau_{u}$ or $f_{v}$, are obtained through Eq. (1a), in which $P_{u}$ is the diagonal force at failure (Bosiljkov et al. 2005a; Türkmen et al. 2020). The parameter $A_{n}$ is the cross-sectional area (parallel to the bed joint) of the specimen. For non-even panel dimensions of depth $d$ and height h, Eq. (1b) appears in the provision. The factor $n$ depends on the perforations $(n=1$ for solid bricks). Note that both Eqs. $(1 \mathrm{a}, \mathrm{b})$ assume that the stress fields form at $45^{\circ}$ to the bed joints.

The same type of test was used to assess the indirect tensile strength of masonry (Eq. 1c) from 'diametral testing of brickwork discs' (Stafford-Smith et al. 1970), or by 'cutting a square panel of brickwork' (Hendry 1997). In these tests, the bed joints are orientated at $45^{\circ}$ to the direction of loading. The parameter $\mathrm{P}_{\mathrm{u}}$ in (Eq. 1c) is the diagonal force at failure, $\mathrm{D}$ is the disc diameter, and $\mathrm{t}$ is the panel thickness. Transforming the circular shape of diameter $D$ to a rectangular panel of depth/width $d$ and height $h(\pi D=2(d+h))$, 
Eq. (1c) reduces to Eq. (1d). The latter is given in the revised Eurocode 8 provisions (CEN 2018, SC8 2018) for the assessment of 'diagonal tensile strength of masonry' from diagonal compressive tests. As noted above, Eq. $1 \mathrm{a}-\mathrm{d}$ assume a $45^{\circ}$ orientation of the bed joints to the load direction, whilst the shoe size, inherent uneven geometry of the slop-moulded bricks, and slightly variable mortar joint thickness, can produce stress fields that deviate from $45^{\circ}$, and these equations can make allowance for this deviation. This has been used to assess the compression-shear interaction of mortar joints on core samples (Pelà et al. 2017).

The angle of deformation $\gamma$, or shear strain as defined by ASTM E519-02 (ASTM 2002), is the sum of the absolute vertical and horizontal strains, $\varepsilon_{\mathrm{v}}$ and $\varepsilon_{\mathrm{h}}$, respectively (Eq. 2). The strain values were obtained from full-field DIC measurements using a virtual gauge of $900 \mathrm{~mm}$ length as shown in Fig. 3a. The shear stress $f_{v}$ corresponding to the diagonal force at failure, diagonal tensile strength $f_{t}$, and the stiffness $G$ are given in Table 1. The stiffness $\mathrm{G}$ was evaluated within the elastic regime, corresponding to $10-40 \%$ of the ultimate capacity.

$$
\begin{gathered}
\tau_{u}=f_{v}=\frac{P_{u}}{\sqrt{2} A_{n}} \quad \text { where } A_{n}=h t \\
f_{v}=\frac{0.707 \cdot P_{u}}{A_{n}} \quad \text { where } A_{n}=\left(\frac{d+h}{2}\right) t \cdot n \\
f_{t}=\frac{2 P_{u}}{\pi D t} \\
f_{t}=\frac{P}{(d+h) t} \\
\gamma=\left|\varepsilon_{v}\right|+\left|\varepsilon_{h}\right|
\end{gathered}
$$

As indicated by the results in Fig. 5 and Table 1, a direct comparison between the average stress-strain of dry and wet specimens, shows that the moisture reduced both the stiffness and the strength, albeit with different extents in the two batches. The average shear stiffness of the DA-W and DB-W wet specimens was reduced by $39 \%$ and $32 \%$, respectively, compared to the corresponding DA-D and DB-D dry panels. On the other hand, the average shear strength of the DA-W and DB-W wet specimens was reduced by $14 \%$ and $43 \%$, respectively, compared to the corresponding DA-D and DB-D dry panels. As shown in Table 1, the average strength and stiffness of DA-D, DB-D and DA-W series were obtained from three or more specimens, whilst for DB-W the average vales were obtained from only two specimens. Hence the results from the DB-W series are only informative Table 2.

In terms of the crack kinematics, similar behaviour was observed during tests on both air-dry and wet specimens. The typical crack patterns illustrated in Fig. 6, obtained from full-field DIC measurements, indicate a typical brittle panel response with failure surfaces following the principal tensile stresses within the specimen. The response of Specimen DA-D1 was characterised by loss of bond at a horizontal bed joint at the centre of the 


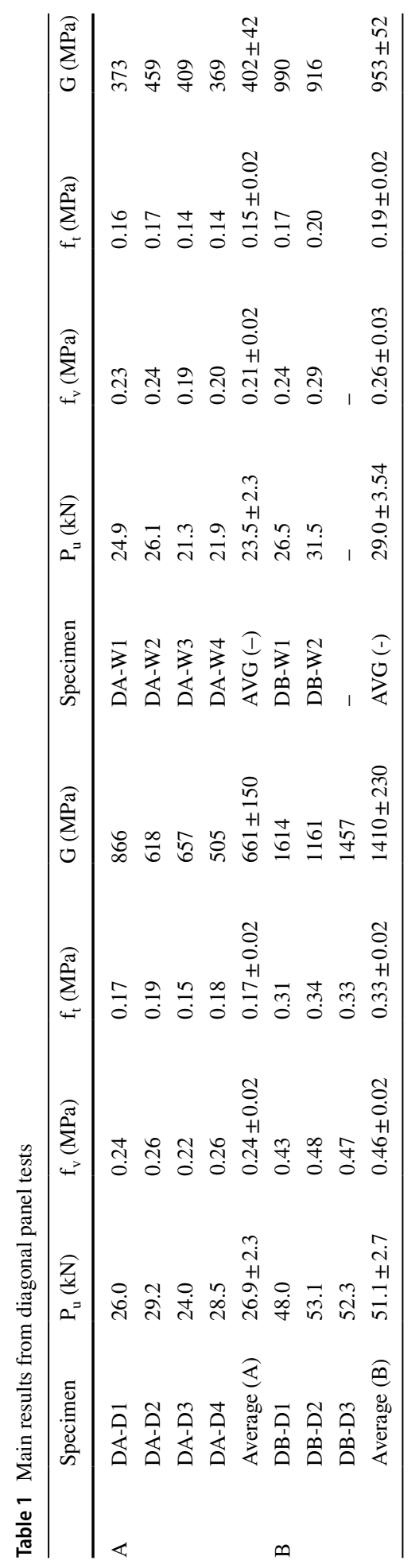


Table 2 Results from compressive strength $\mathrm{f}_{\mathrm{mc}}$ tests on cylindrical cores (in $\mathrm{MPa}$ )

\begin{tabular}{llllllll}
\hline & Specimens & \multicolumn{2}{l}{ Sample } & \multicolumn{3}{l}{ AVG } \\
\cline { 3 - 7 } & & 1 & 2 & 3 & 4 & 5 & \\
\hline A & DA-D & 5.24 & 5.21 & 5.93 & 5.31 & 5.06 & $5.21 \pm 0.11$ \\
& DA-W & 4.33 & 4.71 & 4.59 & 3.41 & 5.10 & $4.36 \pm 0.71$ \\
& WA-D & 5.16 & 5.79 & 4.88 & 5.03 & 5.33 & $5.24 \pm 0.35$ \\
& WA-W & 4.88 & 4.34 & 4.81 & 5.76 & 4.06 & $4.77 \pm 0.65$ \\
B & DB-D & 5.66 & 5.72 & 5.87 & 6.78 & 6.40 & $6.08 \pm 0.49$ \\
& DB-W & 4.86 & 5.12 & 4.84 & 4.64 & - & $4.87 \pm 0.19$ \\
& WB-D & 7.48 & 6.06 & 4.76 & 8.37 & 6.26 & $6.59 \pm 1.47$ \\
& WB-W & 5.48 & 6.28 & 6.37 & - & - & $6.04 \pm 0.49$ \\
\hline
\end{tabular}

panel at around $90 \%$ of the peak capacity. The critical crack propagated following the top and bottom plates through vertical and horizontal bed joints in a stepped mode. As shown in Fig. 6a failure occurred due to a single diagonal crack. For the wet Specimen DA-W3, the failure patterns illustrated in Fig. 6b resembled those of their corresponding dry counterparts. However, the first strain concentrations associated with loss of bond at the brickto-mortar interface occurred between 73 and $75 \%$ of their ultimate strength. In addition to stiffness and strength reduction due to moisture, the above results indicate that the bond properties are also influenced by the moisture content. As shown in Fig. 6c, Specimen DB-D2 had a similar failure crack to that of DA-D1, initiating at the panel centre around $90 \%$ of ultimate. For Specimen DB-W1, for which the crack pattern at failure is shown in Fig. 6d, the first visible strain concentration at a horizontal bed joint was observed around $85 \%$ of peak load.

On the other hand, the results of the compression tests on cylindrical masonry cores can be used to evaluate the uniaxial response without the influence of shear and contribute to constructing the masonry shear-compression strength envelope described below in this paper. As shown in Fig. 7, the response of cylinders in compression exhibits a typical brittle response with significant softening immediately after the peak. It is worth noting that the relatively high strength obtained from compression tests on cores, particularly for the dry Batch B cores (DB-D and DB-D cylinders), may not be representative for some

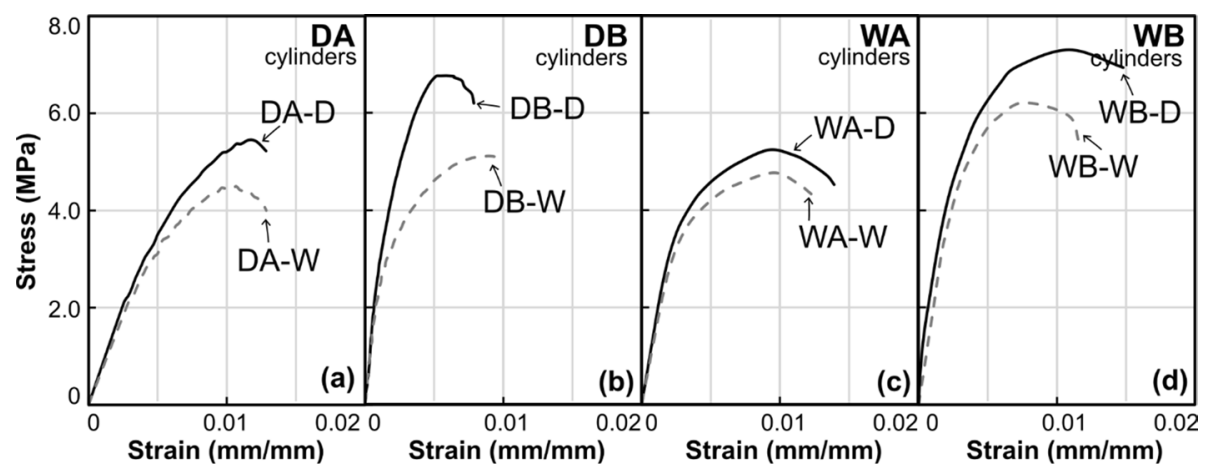

Fig. 7 Average stress-strain response in compression for cylindrical cores corresponding to specimen groups: a DA-D and DA-W, b DB-D and DB-W, c WA-D and WA-W, d WB-D and WB-W 


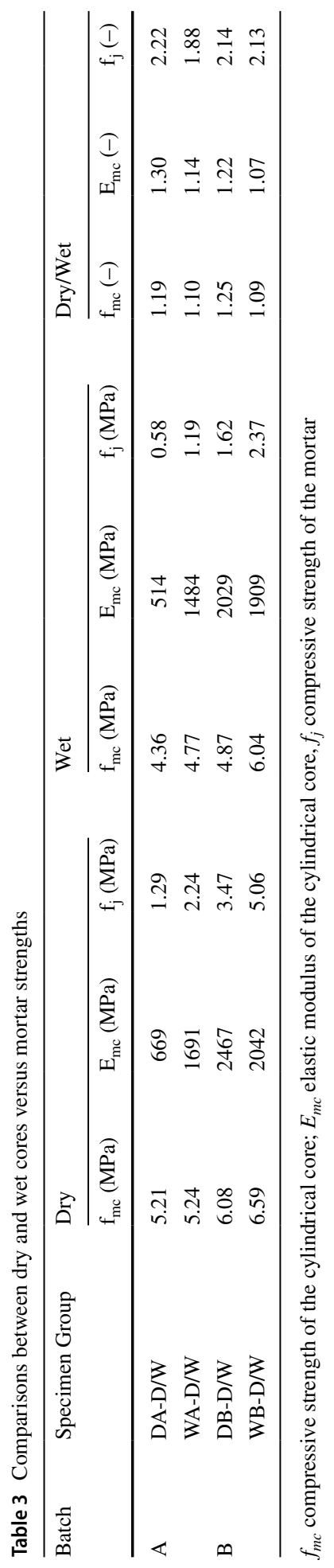


forms of historic structures. However, as noted before, the range of strengths for historic masonry can vary significantly, and typical compressive strengths of masonry cores of similar structures built during the same Mamluk period in Cairo were consistent with the ranges obtained herein (El-Attar et al. 2005).

Based on the stress-strain $(\sigma-\varepsilon)$ curves from Fig. 7 and the results in Table 3, it can be observed that both the elastic modulus and the compression strength are notably influenced by the moisture, with reduction factors in the range of $7-23 \%$ and $8-20 \%$, respectively. As shown in the table, the strength of the wet specimens, compared to the dry counterparts, reduced by a consistent ratio of about $8-9 \%$ for the cores obtained from the large walls, whilst a wider range of 16-20\% resulted from the cores obtained from the diagonal panels. Although previous tests on masonry elements have shown larger differences between dry and wet conditions, this is highly dependent on the material porosity, and such ranges are common for materials similar to those investigated in this paper (Sathiparan and Rumeshkumar 2018; Amade et al. 2004; Bompa and Elghazouli 2020b).

\subsection{Large scale wall tests}

This section describes the main test results from the four large-scale cyclic tests as shown in Fig. 4. These included two dry walls (WA-D and WB-D) and two wet walls (WA-W and WB-W). As mentioned above, these specimens were subjected to an initial gravity load of about 1.0 MPa and increasing lateral displacements. The lateral load versus drift (P- $\Delta$ ) curves are depicted in Fig. 8, the ultimate crack patterns are illustrated in Fig. 9, and the main parameters and results are also given in Tables $4,5,6,7,8$. The crack patterns on the
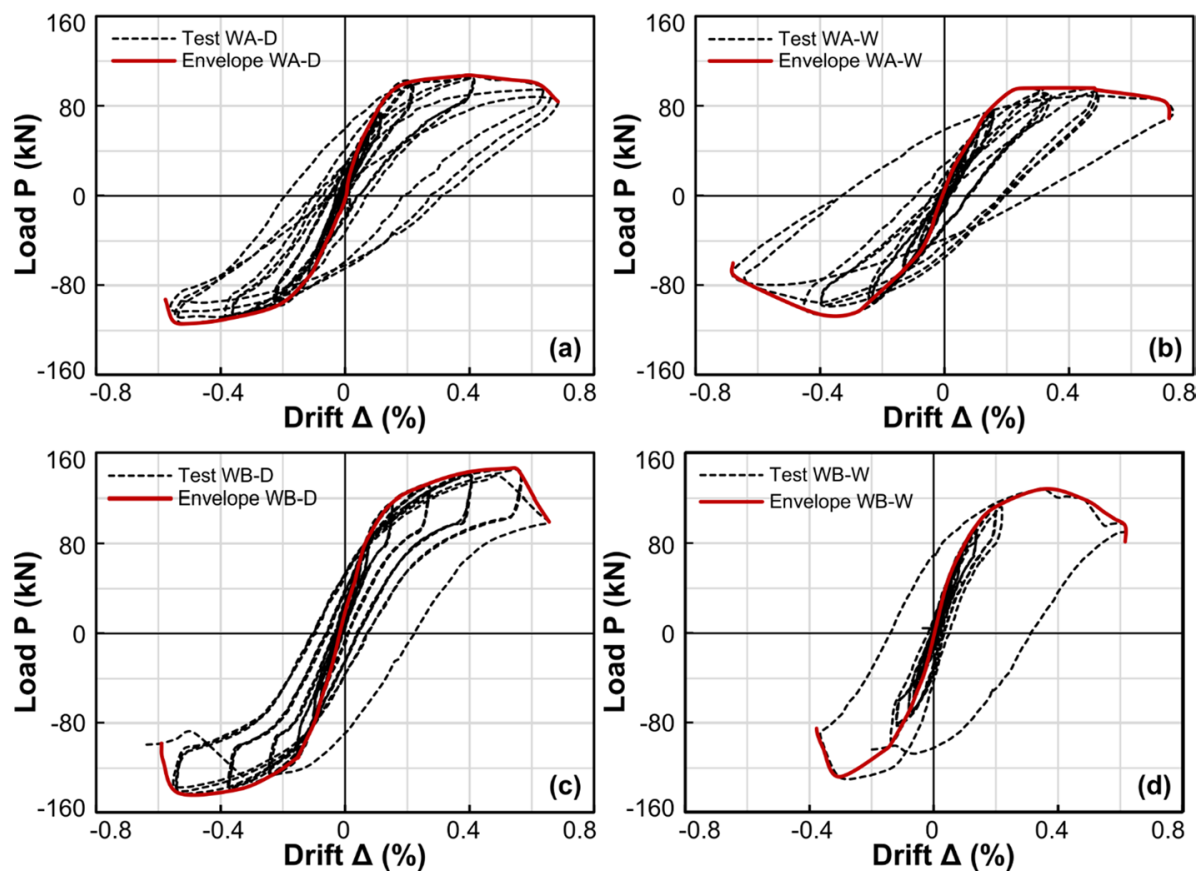

Fig. 8 Lateral load-drift response of the large scale walls: a WA-D, b WA-W, c WB-D, d WB-W 

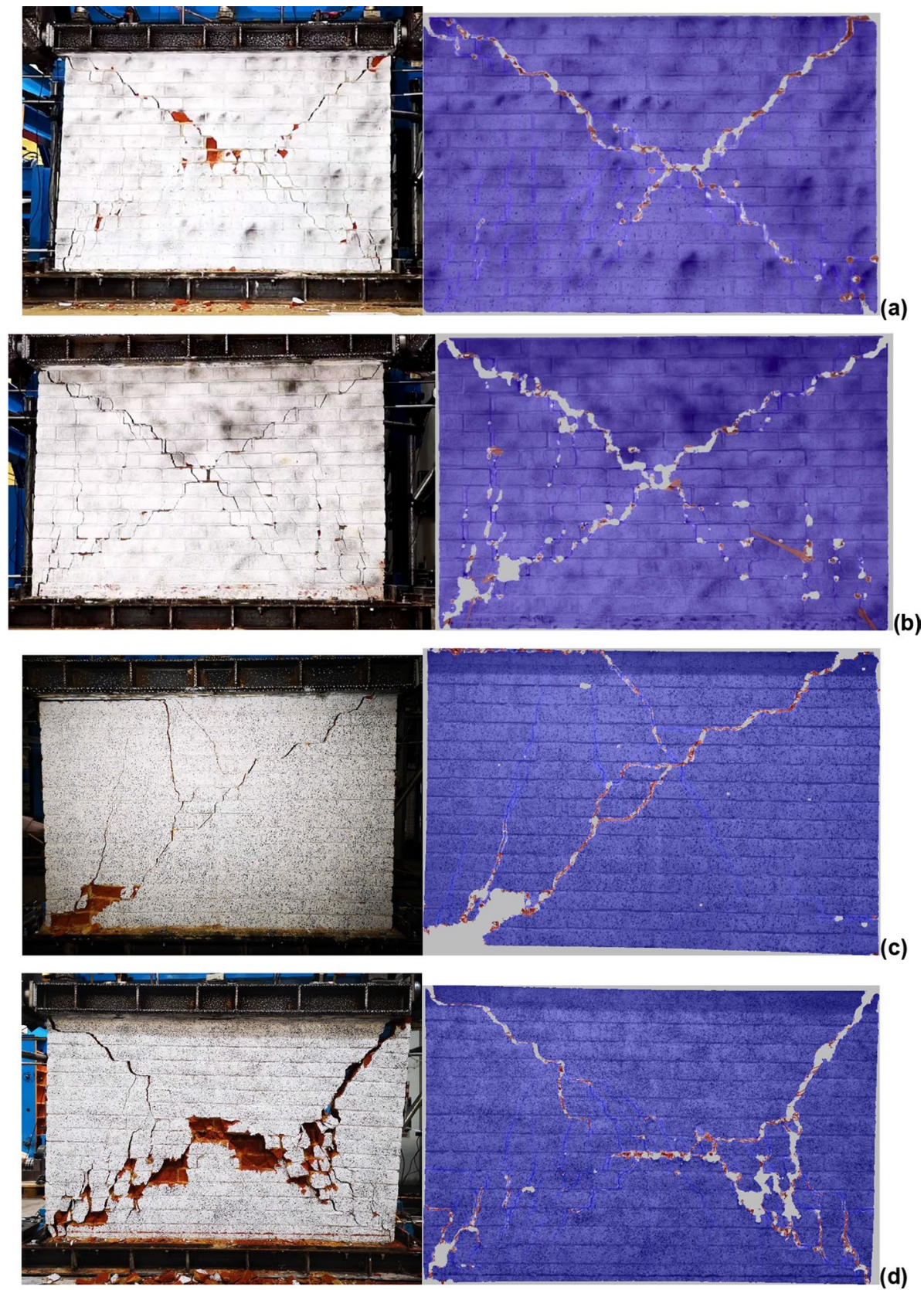

Fig. 9 Failure characteristics for Specimens a WA-D, b WA-W, c WB-D, d WB-W (left: final crack patterns at ultimate, right: strain maps from full-field DIC measurements)

left-hand side of Fig. 9 show the failures after each test, whilst those shown on the righthand side of the figure are strain maps obtained from full-field DIC measurements. 
Table 4 Main parameters of large-scale tests

\begin{tabular}{llllllll}
\hline & Specimen & $\mathrm{h}(\mathrm{mm})$ & $\mathrm{d}(\mathrm{mm})$ & $\mathrm{t}(\mathrm{mm})$ & $\mathrm{N}(\mathrm{kN})$ & $\mathrm{P}_{\mathrm{u}}(\mathrm{kN})$ & $\Delta_{\mathrm{u}}(\%)$ \\
\hline A & WA-D & 1275 & 1910 & 110 & 227.3 & 110.6 & 0.62 \\
& WA-W & 1275 & 1910 & 110 & 225.1 & 101.6 & 0.65 \\
B & WB-D & 1275 & 1910 & 110 & 219.9 & 144.3 & 0.73 \\
& WB-W & 1275 & 1910 & 110 & 220.7 & 128.1 & 0.88 \\
\hline
\end{tabular}

Table 5 Main strength and drift values for large-scale walls

\begin{tabular}{ccccllll}
\hline & & $\mathrm{P}_{\mathrm{u}+}(\mathrm{kN})$ & $\mathrm{P}_{\mathrm{u}-}(\mathrm{kN})$ & $\Delta_{\text {peak+ }}(\%)$ & $\Delta_{\text {peak }^{-}}(\%)$ & $\Delta_{\mathrm{u}+}(\%)$ & $\Delta_{\mathrm{u}-}(\%)$ \\
\hline A & WA-D & 107.1 & -114.1 & 0.40 & -0.50 & 0.67 & -0.58 \\
& WA-W & 95.9 & -107.2 & 0.48 & -0.35 & 0.70 & -0.58 \\
\multirow{2}{*}{ B } & WB-D & 146.3 & -142.2 & 0.53 & -0.53 & 0.61 & -0.58 \\
& WB-W & 127.0 & -129.2 & 0.35 & -0.31 & 0.57 & -0.36 \\
\hline
\end{tabular}

Positive sign $(+)$ represent values for the push/positive cycle, whilst negative sign is for the pull/negative loading direction

Table 6 Main stiffness parameters for the large-scale tests

\begin{tabular}{llllllll}
\hline & Specimen & $\begin{array}{l}\mathrm{K}_{\text {test+ }}(\mathrm{kN} / \\
\mathrm{mm})\end{array}$ & $\begin{array}{l}\mathrm{K}_{\text {test- }}(\mathrm{kN} / \\
\mathrm{mm})\end{array}$ & $\begin{array}{l}\mathrm{K}_{\text {test }}(\mathrm{kN} / \\
\mathrm{mm})\end{array}$ & $\mathrm{K}_{0}(\mathrm{kN} / \mathrm{mm})$ & $\begin{array}{l}\mathrm{K}_{\text {eff }}(\mathrm{kN} / \\
\mathrm{mm})\end{array}$ & $\mathrm{K}_{\mathrm{el}}(\mathrm{kN} / \mathrm{mm})$ \\
\hline A & WA-D & 44.8 & 52.5 & 48.7 & 86.3 & 45.7 & 53.6 \\
& WA-W & 48.7 & 48.5 & 48.6 & 66.6 & 41.8 & 47.1 \\
$\mathrm{~B}$ & WB-D & 66.1 & 70.7 & 68.4 & 76.9 & 62.0 & 72.7 \\
& WB-W & 54.3 & 55.0 & 54.6 & 75.6 & 60.5 & 71.1 \\
\hline
\end{tabular}

Table 7 Test and elasto-plastic numerical analysis

\begin{tabular}{lllrllll}
\hline & Specimen & $\mathrm{N}(\mathrm{kN})$ & $\mathrm{P}(\mathrm{kN})$ & $\mathrm{f}_{\mathrm{m}}(\mathrm{MPa})$ & $\mathrm{E}_{\mathrm{m}}(\mathrm{MPa})$ & $\sigma_{\mathrm{n}}(\mathrm{MPa})$ & $\tau_{\max }(\mathrm{MPa})$ \\
\hline A & WA-D & 227.3 & 110.6 & 4.34 & 651 & 2.19 & 1.44 \\
& WA-W & 225.1 & 101.6 & 3.57 & 536 & 1.92 & 1.05 \\
& DA-D & - & 26.9 & 3.68 & 551 & 0.40 & 0.45 \\
& DA-W & - & 23.6 & 2.88 & 432 & 0.35 & 0.40 \\
B & WB-D & 219.9 & 144.3 & 5.54 & 831 & 1.74 & 1.41 \\
& WB-W & 220.7 & 128.1 & 4.39 & 659 & 1.64 & 1.16 \\
& DB-D & - & 51.1 & 4.95 & 742 & 0.76 & 0.85 \\
& DB-W & - & 29.0 & 3.92 & 588 & 0.44 & 0.57 \\
\hline
\end{tabular}

\subsubsection{Load-deformation and crack patterns}

The response of the first ambient-dry wall, Specimen WA-D, was largely symmetric in both loading directions up to about $90 \%$ of the peak load, with an initial stiffness $\mathrm{K}_{0}=86.3$ $\mathrm{kN} / \mathrm{mm}$. This initial stiffness corresponds to the slope of the line connecting the positive 
Table 8 Comparison between test results and assessment equations

\begin{tabular}{llllll}
\hline & & $\mathrm{V}_{\text {test }}(\mathrm{kN})$ & $\mathrm{V}_{\mathrm{f}}(\mathrm{kN})$ & $\mathrm{V}_{\mathrm{s}}(\mathrm{kN})$ & $\mathrm{V}_{\mathrm{d}}(\mathrm{kN})$ \\
\hline $\mathrm{A}$ & WA-D & 110.6 & 118.2 & 97.2 & 113.2 \\
& WA-W & 101.6 & 107.8 & 93.2 & 102.7 \\
$\mathrm{~B}$ & WB-D & 144.3 & 125.5 & 94.2 & 134.4 \\
& WB-W & 128.1 & 116.8 & 91.4 & 123.6 \\
\hline
\end{tabular}

and negative extreme points in the first cycle. The maximum lateral load carrying capacity was $\mathrm{P}_{\mathrm{u}+}=107.1 \mathrm{kN}$ and $\mathrm{P}_{\mathrm{u}-}=--14.1 \mathrm{kN}$, respectively. As shown in Fig. 8a, this corresponded to a drift at peak of $\Delta_{\text {peak }+}=0.40 \%$ and $\Delta_{\text {peak- }}=0.50 \%$ in the push (positive) and pull (negative) cycle, respectively. As observed from the load-drift curve, after $\Delta>0.30 \%$ the stiffness and lateral load attained for each level of applied deformation decreased with increasing cycles, indicating a higher level of cyclic degradation. The first signs of diagonal cracking were observed at a negative (pull) cycle at $\Delta=0.25 \%$.

The diagonal crack closed during unloading, while at the same drift level in the push (positive cycle) a diagonal crack appeared, nearly perpendicular to that occurring from the pull cycle. The overall behaviour was largely governed by shear with no notable sign of flexural bed joint opening. The ultimate failure patterns in Fig. 9a, indicate that the failure was largely due to diagonal tension. Failure was characterised by sliding of the two bodies separated by the diagonal crack following each loading direction. The ultimate drifts corresponding to a $20 \%$ reduction in capacity were $\Delta_{\mathrm{u}+}=0.67 \%$ and $\Delta_{\mathrm{u}-}=0.58 \%$ in the positive and negative cycle, respectively.

The initial stiffness and maximum lateral load carrying capacity, in the positive and negative directions of Specimen WA-W, were $\mathrm{K}_{0}=66.6 \mathrm{kN} / \mathrm{mm}, \mathrm{P}_{\mathrm{u}+}=95.9 \mathrm{kN}$ and $\mathrm{P}_{\mathrm{u}-}=-07.2 \mathrm{kN}$, respectively. This corresponded to a drift $\Delta_{\text {peak }+}=0.48 \%$ and $\Delta_{\text {peak- }}=0.35 \%$ in the push (positive) and pull (negative) cycle, respectively. Compared to its dry counterpart, the wet Specimen WA-W had a less symmetric overall load-drift response, particularly in the post-cracking regime. As indicated in Fig. 8b, the ultimate drifts were slightly different for the two directions. The first visible diagonal crack occurred in the second positive (push) cycle at a drift level $\Delta=0.30 \%$. The diagonal crack closed during unloading. As for its dry counterpart, the behaviour was largely governed by shear with minimum influence from flexure, with failure eventually occurring due to diagonal tension, as shown by the final crack patterns in Fig. 9b.

The complete load-drift (P- $\Delta$ ) curve of the air-dry Specimen WB-D and its envelope are illustrated in Fig. 8c and the failure patterns are shown in Fig. 9c. The lateral deformation at peak corresponded to a drift of $\Delta_{\text {peak+ }}=0.53 \%$ and $\Delta_{\text {peak- }}=0.53 \%$ in the push (positive) and pull (negative) cycle (Table 5). The response of the specimen was largely symmetric in both loading directions with an elastic stiffness $\mathrm{K}_{0}=76.9$ $\mathrm{kN} / \mathrm{mm}$. The corresponding maximum lateral load carrying capacity was $\mathrm{P}_{\mathrm{u}+}=146.3$ $\mathrm{kN}$ and $\mathrm{P}_{\mathrm{u}-}=142.2 \mathrm{kN}$, respectively. The transition between elastic and inelastic stiffness occurred at a lateral load (P) around $80 \mathrm{kN}$ in both loading directions. This corresponded to a drift ratio of about $\Delta=0.1 \%$ and was associated with initial signs of cracking. At this stage, the behaviour was largely governed by flexure.

As observed from the P- $\Delta$ response, after each first cycle applied at $\Delta>0.1 \%$ the stiffness and lateral load attained for each level of deformation decreased with the increasing cycles. The first visible diagonal crack occurred in the negative (pull) cycle at a drift level $\Delta=0.53 \%$ and closed during unloading. At the same drift level in the 
push (positive cycle) a diagonal crack nearly perpendicular to that occurring from the pull cycle was initiated. This corresponded to the maximum capacity of the specimen. At the third displacement cycle in the positive direction, the specimen failed and was unable to reach the load attained in the previous cycles. Failure was characterised by crushing at the toe and sliding of the two bodies separated by the diagonal crack. The ultimate drifts, assumed to correspond to $20 \%$ reduction in load carrying capacity, were $\Delta_{\mathrm{u}+}=0.61 \%$ and $\Delta_{\mathrm{u}-}=0.58 \%$.

Specimen WB-W was tested under combined axial load and increasing lateral cyclic displacements, in wet conditions. The full load-drift $(\mathrm{P}-\Delta)$ and envelope curves are depicted in Fig. 8d, while the crack patterns at failure are shown in Fig. 9d. The response of the specimen was largely symmetric in both loading directions until about $75 \%$ of the peak load. A noticeable reduction in stiffness started at a lateral load of about $35 \mathrm{kN}(\Delta=0.07 \%)$ then at $95 \mathrm{kN}(\Delta=0.25 \%)$. The initial stiffness was $\mathrm{K}_{0}=75.6 \mathrm{kN} / \mathrm{mm}$. The maximum lateral load carrying capacity was $\mathrm{P}_{\mathrm{u}+}=127.0 \mathrm{kN}$ and $\mathrm{P}_{\mathrm{u}-}=129.2 \mathrm{kN}$ in the two directions. This corresponded to a drift $\Delta_{\text {peak+ }}=0.35 \%$ and $\Delta_{\text {peak- }}=0.31 \%$ in the push (positive) and pull (negative) cycles, respectively.

The behaviour of WB-W was initially governed by flexure. Subsequently, the stiffness and lateral load attained for each level of applied deformation decreased with increasing cycles, indicating a higher level of cyclic degradation, particularly in the negative loading direction. The first signs of diagonal cracking were observed at a negative (pull) cycle after $\Delta=0.20 \%$, with the diagonal crack closing during unloading. At the same drift level in the push (positive cycle), a diagonal crack nearly perpendicular to that occurring from the pull cycle developed, corresponding to the maximum capacity of the specimen. Failure was characterised by sliding of the two bodies separated by the diagonal crack following each loading direction.

\subsubsection{Response envelopes and ductility levels}

The envelopes of the lateral load-drift P- $\Delta$ curves, as shown in Fig. 10a, were determined from the peak values of the first cycle for each drift level for the large-scale wall tests. Comparing the response of the wet (WA-W and WB-W) and dry (WA-D and WB-D) specimens, the influence of moisture on the capacity of the members becomes evident. The reduction in average lateral strength was up to $11 \%$ ( $9 \%$ for WA and $11 \%$ for WB
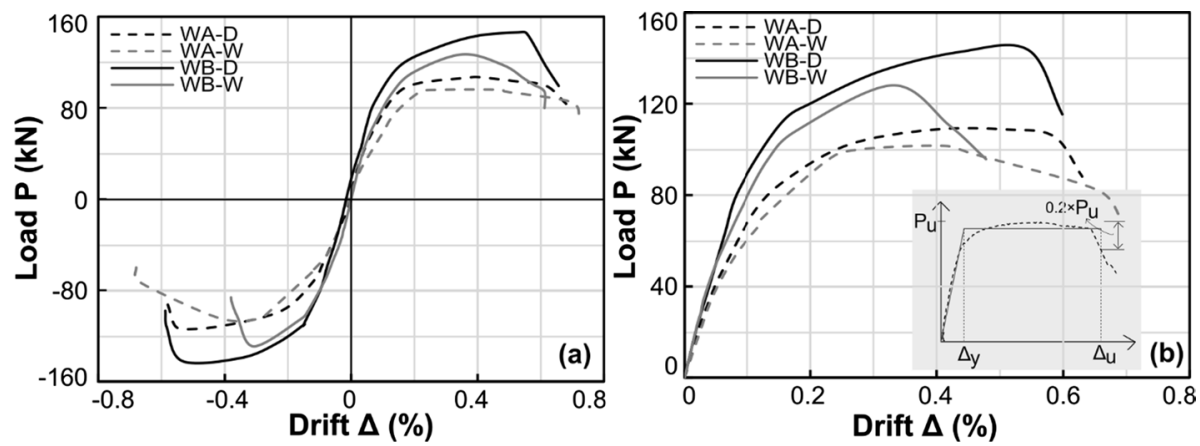

Fig. 10 Lateral displacement-drift (P- $\Delta$ ) response: a envelopes of cyclic tests, $\mathbf{b}$ average envelopes of two directions 
specimens). It is worth noting again, that the wet-to-dry strength reduction ratios were broadly similar for the large walls (WA-D/W and WB-D/W) as well as for Batch A diagonal panels (DA-D/W). These reductions were consistently about $10 \%( \pm 2 \%)$.

In terms of failure patterns, the response of both WA-W and WA-D walls was largely symmetric and governed by shear, ultimately failing in diagonal tension with the two diagonal cracks intersecting around the centre of the wall. On the other hand, Specimens WB-D and WB-W had a flexure-governed response indicated by opening of an interface gap between the supporting steel plate and the first brick course. Unreinforced masonry can develop such response, as often explained by aspects of non-linear elastic behaviour (Petry and Beyer 2015b). This is mainly attributed to the reduction of the compression zone with the increase in lateral displacement and the associated decrease in effective stiffness of the member. The contribution of the tension side of the wall also gradually diminishes as cracks open along the horizontal bed joints.

As discussed above, the ductility of the wet walls, in terms of ultimate drift, was broadly similar or lower than that of their dry counterparts, primarily influenced by the post-peak kinematics. Given the influence of moisture on the stiffness and effective yield, perhaps a more representative measure of ductility would be an ultimate-to-yield drift ratio $\left(\mu_{\Delta}=\Delta_{\mathrm{u}} /\right.$ $\Delta_{\mathrm{y}}$ ). With reference to the insert diagram at the bottom right-hand side of Fig. 10b, $\Delta_{\mathrm{y}}$ can be estimated from a simplified bilinear P- $\Delta$ curve by equating areas under the average test P- $\Delta$ envelope and the bilinear P- $\Delta$ idealisation. Using this approach, the drift ductility ratios $\left(\mu_{\Delta}\right)$ are estimated as 4.0 for WA-D, 3.8 for WA-W, 4.0 for WB-D and 3.5 for WB-W. Overall, direct experimental comparison between the cyclic response of the wet and dry specimens shows the negative effect of moisture on the stiffness, capacity and ductility of masonry walls subjected to initial gravity and increasing lateral loads.

To obtain a detailed insight into the specimen response, particularly with regard to wall curvatures and rotations, the DIC data was analysed. Firstly, virtual vertical strain gauges of $80 \mathrm{~mm}$ length that included a bed joint and about half of the two adjacent bricks were assigned at eight bed joints (Fig. 4a). The gauges were positioned at each of the first five bed joints and then at the seventh, tenth, thirteenth and fifteenth. This arrangement is sufficient to obtain a relatively refined curvature $(\phi)$ distribution within the expected critical zone. After obtaining the strain profiles, average curvatures over the wall height were obtained using Eq. (3), in which $\varepsilon_{1 \mathrm{i}}$ and $\varepsilon_{2 \mathrm{i}}$ are the strains at $5 \mathrm{~mm}$ from the wall edges, whilst $1_{\mathrm{w}}$, is the distance between the two gauges $\left(1_{\mathrm{w}},=1900 \mathrm{~mm}\right)$. Note that subscripts 1 and 2 in $\varepsilon_{1 \mathrm{i}}$ and $\varepsilon_{2 \mathrm{i}}$, correspond to compression and tension, respectively, depending on the loading direction. Curvatures were then integrated along the height (h) of the wall to obtain wall rotations $(\theta)$ using Eq. (4) in which i and i-1 denote the current and previous integration step, respectively, whilst $h_{g, i}$ is the gauge length. The rotations were then used to assess the shear and flexural deformations as well as to validate the global lateral displacementdrift (P- $\Delta$ ) response envelopes in Fig. 10 (Mohamed et al. 2014; Beyer et al. 2011).

$$
\begin{gathered}
\phi_{i}=\left(\left|\varepsilon_{1 i}\right|+\left|\varepsilon_{2 i}\right|\right) / l_{w^{\prime}} \\
\theta=\int_{0}^{h} \phi(y) d y=\theta_{i-1}+\left(\phi_{i}-\phi_{i-1}\right) /\left(2 h_{g, i}\right)
\end{gathered}
$$

Figure 11 presents the curvature $(\phi)$ distribution along the wall height, whilst Fig. 12 illustrates the average wall rotations $(\theta)$ along the wall height. Note that for compactness, only positive $\phi$ and $\theta$ distributions for each of the first applied displacement cycle are 


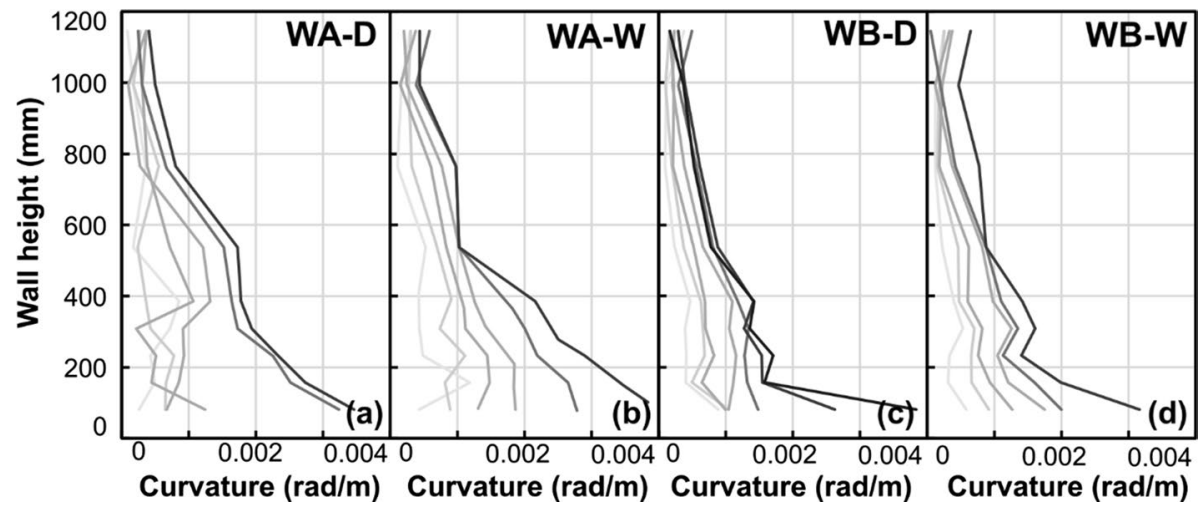

Fig. 11 Curvature distributions along the height of Specimen: a WA-D, b WA-W, c WB-D, d WB-W (light grey curves to the left represent early cycles, whilst dark black curves to the right correspond to peak)

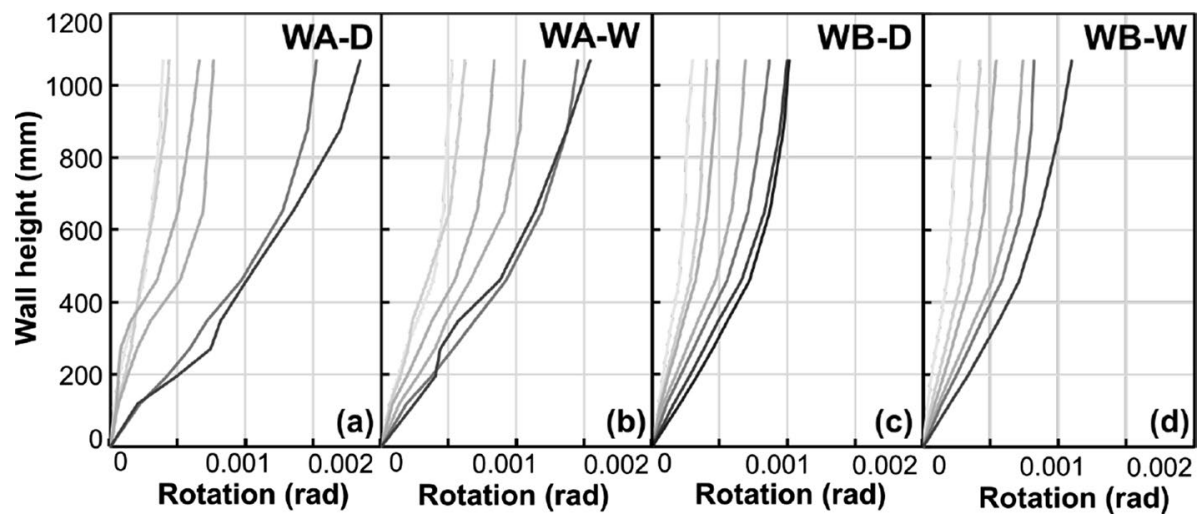

Fig. 12 Rotations along the height of Specimen: a WA-D, b WA-W, c WB-D, d WB-W (light grey curves to the left represent early cycles, whilst dark black curves to the right correspond to peak)

shown. Each curve, from the left to the right of each of the panels in Figs. 11 and 12, correspond to a higher level of applied displacement (i.e. the light grey curves to the left represent the first cycle, whilst the black curves to the right represent the cycle that corresponds to peak). As expected, the curvatures are concentrated at the bottom of the wall within the regions with highest compression stresses at the wall toe. It is also worth noting that the WA walls have a more linear $\phi$ distribution, which may be attributed to the more symmetric shear-dominated response, whilst WB walls show concentrations of $\phi$ within $15 \%$ of the wall height at the bottom due to a higher influence from bending. On the other hand, the $\theta$ distributions, shown in Fig. 12, follow a pattern characteristic for members tested under lateral displacement and co-existing gravity load, where the rotations increase gradually from the base along the wall height. 


\section{Analytical assessments}

\subsection{Shear-compression failure envelopes}

As noted before, the small-scale tests described in this paper can be used to evaluate the shear-compression $(\tau-\sigma)$ failure envelopes. This enables a detailed insight into the moisture effects on the mechanical properties of masonry, and permits a comparison with the behaviour of the large-scale tests in subsequent sections. The shear sliding properties of masonry joints are generally obtained from triplet tests, while the diagonal tensile strength is typically assessed from diagonal panel tests, yet the tensile strength can also be obtained from triplet tests. The failure envelope is then capped by compression crushing (Flores et al. 2013; Li et al. 2005). The shear strength $\left(\tau_{\mathrm{s}}=\mathrm{f}_{\mathrm{v} 1}\right)$ through shear sliding is generally represented by a Mohr-Coulomb criterion (Eq. 5a), which depends on the precompression stress $\sigma$ and the model coefficients c and $\mu$ (BSI 2004; Li et al. 2005; Hendry 1997; CEN 2018; BSI 2005a). As given in Eq. 5b, the cohesion $c$ is referred to in codified provisions as the initial shear strength $\mathrm{f}_{\mathrm{v} 0}$ and is representative of cases without normal load $(\sigma=0)$ (BSI 2005a). The slope of the Mohr-Coulomb criterion $\mu=\tan \phi$ is typically considered in codes as a value of 0.4 , which is expected to lead to a lower bound estimate of the shear sliding strength.

A recent complementary study carried out by the authors on triplets subjected to shear loading and varying levels of precompression, indicated that the initial shear strength was $\mathrm{f}_{\mathrm{v} 0}=0.165 \mathrm{MPa}$ for dry specimens and $\mathrm{f}_{\mathrm{v} 0}=0.100 \mathrm{MPa}$ for wet specimens (Bompa and Elghazouli 2020a). The triplets consisted of bricks which had identical properties to those from this paper, and the lime mortar had a strength similar to that in the WA-D and DA-D specimens. The slope $(\mu)$ of the linear function from Eq. 5a was however about $50 \%$ higher than that suggested by codified guidance (BSI 2005a), with $\mu=0.62$ for dry joints and $\mu=0.58$ for wet joints. These values, combined with the results from tests on three triplet specimens extracted from undamaged regions of the tested walls, are used to plot the first region of the shear-compression $(\tau-\sigma)$ failure envelope for shear-sliding of dry and wet masonry joints in Fig. 13a,b. The linear representation of $\tau-\sigma$ for shear sliding, using Eq. 5c, is marked with '(1)' and represented by an inclined dashed red line in Fig. 13a.

It is worth noting that the shear sliding parameters (c and $\mu$ ) from Eq. 5 refer to singular brick-mortar interfaces such as those in triplet specimens. To obtain these
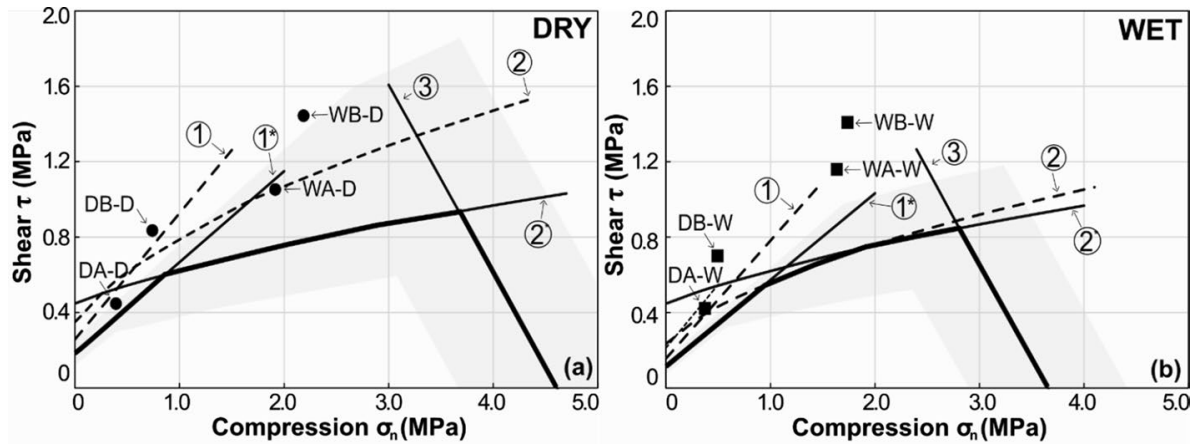

Fig. 13 Shear-compression envelopes and test results a Dry specimens, b Wet specimens 
parameters for masonry elements of larger sizes, the interface parameters $\mathrm{c}$ and $\mu$ would need to be replaced with c' and $\mu$ ' using Eq. $5 \mathrm{~d}$,e, in which $\mathrm{h}_{\mathrm{b}}$ and $\mathrm{l}_{\mathrm{b}}$ are the height and length of the brick unit, respectively (Mann and Müller 1982). By considering the size effect, the shear stress limit condition moves to lower stress levels. Hence, the inclined dashed line, marked with '(1)', is translated to the modified sliding limit condition, marked with ' $\left(1^{*}\right)$ ' ( $\mathrm{Li}$ et al. 2005). The local criterion (Eqs. 5a-c) can then be translated into a global criterion $\mathrm{V}_{1}$ depicted by Eq. (5f), in which $\sigma_{0}$ is the stress in the compressed area of the member $\left(\sigma_{0}=\mathrm{N} / \mathrm{d}^{\prime} / \mathrm{t}\right), \mathrm{N}$ is the axial load, d' is the compressed depth at the end of the section of the member and $t$ is its thickness (CEN 2018).

$$
\begin{gathered}
\tau_{s}=c+\mu \sigma \\
f_{v 1}=\min \mid \begin{array}{l}
f_{v 0}+0.4 \sigma \\
0.065 f_{b}
\end{array} \\
f_{v 1}=f_{v 0}+\mu \sigma \\
\mu^{\prime}=\frac{\mu}{1+2 \mu\left(h_{b} / l_{b}\right)} \\
c^{\prime}=\frac{f_{v 0}}{1+2 \mu\left(h_{b} / l_{b}\right)}=f_{v 0}^{\prime}=\frac{1+2 \mu\left(h_{b} / l_{b}\right)}{1+\mu^{\prime} \sigma} \\
f_{v 1}^{\prime}=f_{v 0}^{\prime}+\mu^{\prime} \sigma \\
V_{1}=f_{v 1} A_{n}=\left(f_{v 0}^{\prime}+\mu^{\prime} \sigma_{0}\right) t d^{\prime}
\end{gathered}
$$

The response of the diagonal panel tests is characterised by principal stresses acting in the two main specimen directions. The direction of load application is characterised by a compression stress field, with a perpendicular-acting tension field which leads to splitting or stepped sliding along the mortar joints, depending on the properties of the bricks and mortar (Malyszko 2004).

To assess the shear strength $\mathrm{f}_{\mathrm{v} 2}$ for the stepped sliding the failure criterion (Hendry 1997), referred to as the 'principal tensile stress criterion', precompression normal to the bed joints $\left(\sigma_{0}\right)$, and the diagonal tensile strength $f_{t}$ are required as an input parameter (Eq. 6a,b). The latter corresponds to the masonry tensile strength $f_{t}$ obtained from shear tests on wall specimens or, in this case, diagonal panels (Eq. 1c,d) (Stafford-Smith et al. 1970; Hendry 1997; CEN, TC250, SC8 2018), which is distinct from the tensile strength of bed joints (Magenes and Calvi 1997). The term $\mathrm{P}_{\mathrm{u}}$ in Eq. $6 \mathrm{~b}$ is the diagonal force at failure, whilst $d$ and $h$ are the depth/width and height of the panel (CEN 2018). By considering the member geometry, this local criterion can be transformed to a global criterion (Eq. 6c). Note that according to Eurocode 8 and several previous studies, $\sigma_{0}$ is the mean vertical stress in the transverse section of the panel, which is assessed by dividing the axial load $\mathrm{N}$ divided by the full cross-sectional area of the member $\mathrm{d} \times \mathrm{t}$ (CEN 2018; Magenes and Calvi 1997; Vanin et al. 2017; Beyer 2012), whilst in the original model this refers to the compressed part of the cross-section (Mann and Müller 1982). 
The principal tensile stress criterion (Eq. 6a) (Hendry 1997) accounts for shear failures governed by sliding at the bed joints, whilst tests showed that for high axial loads, and/or strong mortars, failure may be triggered by shear-tensile cracking of bricks (Magenes and Calvi 1997). This criterion ( $\left.f_{\mathrm{v} 2 \text {,lim }}\right)$, depicted by Eq. (6d), is based on the tensile strength of the bricks $\mathrm{f}_{\mathrm{bt}}$ (Hendry 1997; Magenes and Calvi 1997). The parameter $\sigma_{0}$ in Eq. (6d) is the mean vertical stress in the transverse section of the panel, as for Eq. (6a). Although in its original form this criterion requires the tensile brick strength, it has been used as a limiting criterion by accounting for the 'tensile strength of masonry' (Li et al. 2005). The brick tensile strength $\mathrm{f}_{\mathrm{bt}}$ can either be obtained from tests, by correlation with the compressive strength of units (CEN, TC250, SC8 2018; Hendry 1990; Ghiassi et al. 2019), or using Eq. (66) (Li et al. 2005; Türkmen et al. 2020; Ghiassi et al. 2019; Silva et al. 2008), yet the latter may be limited to only some forms of masonry. Based on available literature, the tensile strength $\mathrm{f}_{\mathrm{bt}}$ of solid clay bricks is $0.033 \times \mathrm{f}_{\mathrm{b}}$ (Hendry 1990), $0.05 \times \mathrm{f}_{\mathrm{b}}$ (Ghiassi et al. 2019) or $0.10 \times \mathrm{f}_{\mathrm{b}}(\mathrm{CEN} 2018)$.

Equation (6d) can be transformed into a global strength criterion $V_{2, l i m}$ (Eq. 6e) by considering the member geometry and a factor $\left(1-\alpha_{v}\right)$ that represents a 2.3 multiplier to the denominator (Beyer 2012). The $\alpha_{v}=h_{0} / d$ coefficient that is a function of the distance from the support to point of contraflexure $h_{0}$ and wall depth $d$, incorporating the effects of complex stress distribution, crack propagation and shear-flexure interaction (Magenes and Calvi 1997). For the purpose of constructing the shear-compression envelope in this study, this is not accounted for, as it also does not appear in the expressions of the revised Eurocode 8 (CEN 2018) described later on in this paper.

The test results from Table 1 are used as input in Eq. (6) (Li et al. 2005) to plot the second curve '(2)' of the shear compression $\tau-\sigma$ envelope shown in Fig. 13a,b. The grey region represents the upper and lower bounds for the diagonal tension limiting regime as obtained from the tests and intersects the minimum-maximum ranges of the limiting condition by failure of bricks in splitting, as marked with ' $\left(2^{*}\right)$ ' in the same figure. The lower bound of ' $(2 *)$ ' was assessed using $0.033 \times \mathrm{f}_{\mathrm{b}}$ (Hendry 1990), and the upper bound using $0.10 \times \mathrm{f}_{\mathrm{b}}(\mathrm{CEN} 2018)$.

$$
\begin{gathered}
f_{v 2}=f_{t} \sqrt{1+\frac{\sigma_{0}}{f_{t}}} \\
f_{t}=\frac{P_{u}}{t(d+h)} \\
V_{2}=f_{2} A_{n}=f_{t} \sqrt{1+\frac{\sigma_{0}}{f_{t}}} t d \\
f_{v 2, \lim }=\frac{f_{b t}}{2.3} \sqrt{1+\frac{\sigma_{0}}{f_{b t}}} \\
V_{2, \lim }=f_{v 2, \lim } A_{n}=\frac{f_{b t}}{2.3} \sqrt{1+\frac{\sigma_{0}}{f_{b t}}} t d
\end{gathered}
$$




$$
f_{b t}=\frac{2}{3} \sqrt{f_{m}}
$$

The third failure mode, denoted by '(3)' in Fig. 13a,b, and estimated using Eq. (7a), is used to cap the $\tau-\sigma$ failure envelope and represents the crushing condition of the masonry (Mann and Müller 1982). This third mode depends on the mean vertical stress $\sigma_{0}$ as the axial force $\mathrm{N}$ divided by the full cross sectional area of the member $(\mathrm{d} \times \mathrm{t})$, the average compressive strength of masonry $f_{m}$ estimated here using Eurocode 6 (BSI 2005a) equation and measured material properties (Eq. 7b), depth/width of the panel $\mathrm{d}$ and panel height $\mathrm{h}$. The parameter $f_{b}$ in Eq. (7d) is the compressive strength of the units obtained from tests parallel to the bed joint, in the direction of the applied action effect, and $f_{j}$ is the compressive strength of the mortar as described in Sect. 2.2.1. The local criterion $\mathrm{f}_{\mathrm{v} 3}$ (Eq. 7d) can then be used to determine the corresponding shear force $V_{3}$ (Eq. 7c), where $A_{c}$ is the crosssectional area in compression. As this failure mode did not occur in the tests described in Sect. 3, this is assessed only for comparative purposes. As for the other conditions of the $\tau-\sigma$ representation, the grey region incorporating the inclined line from Figs. 13a,b, marked with '(3)', corresponds to the minimum and maximum compressive strengths assessed using the measured material properties.

$$
\begin{gathered}
f_{v 3}=f_{m}\left(1-\frac{\sigma_{0}}{f_{m}}\right) \frac{d}{h} \\
f_{m}=0.5 f_{b}^{0.7} f_{j}^{0.3} \\
V_{3}=f_{v 3} A_{c}=f_{m}\left(1-\frac{\sigma_{0}}{f_{m}}\right) \frac{d}{h} A_{c}
\end{gathered}
$$

The intersection between the failure criteria described above, determine the $\tau$ - $\sigma$ failure envelope for a given type of masonry. When a pair of stresses $(\tau, \sigma)$ falls on or outside the envelope, this would represent failure.

Besides the $\tau-\sigma$ failure envelope and the test results from the diagonal tests (DA-D, DA-W, DB-D, DB-W), Fig. 13a,b also show the $(\tau, \sigma)$ points from the large-scale wall members (i.e. WA-D, WA-W, WB-D, WB-W). The normal stress $\sigma_{\mathrm{n}}$ and the corresponding maximum shear stress $\tau_{\max }$, depicted in Table 7 and Fig. 13a,b were determined from a simple elastic-plastic analysis using shell elements and simulating the test boundary conditions. The models were subjected to the loads shown in Table 7 and adopted the material properties from the same table. To assess the material stiffness, the masonry compressive strength $\mathrm{f}_{\mathrm{m}}$, assessed with Eq. (7b) and using the measured constituent properties, was multiplied by $\eta=150$, which is representative for lime-mortar masonry under compression (Bompa and Elghazouli 2021; Costigan et al. 2015). The value of $\sigma_{\mathrm{n}}$ was obtained by averaging the stresses in the compressed area of the specimens at mid-height of the bottom brick, whilst the shear stresses $\tau_{\max }$ were obtained from the same cross-section. The position of the test pairs $\left(\tau_{\max }, \sigma_{\mathrm{n}}\right)$ in relation to the $\tau$ - $\sigma$ envelopes in Fig. 13 indicates the governing failure condition, which is in good agreement with the test observations for both the diagonals and the large walls. 


\subsection{Stiffness and strength of large walls}

Based on the test results, the initial stiffness $\mathrm{K}_{0}$ (slope of line connecting positive and negative extreme points in first cycle), the stiffness $\mathrm{K}_{\text {test }}$ (within the range of $10-40 \%$ of the ultimate capacity), and the effective stiffness $\mathrm{K}_{\text {eff }}$ (from a bilinear idealisation, as indicated in the bottom-right insert in Fig. 10b) (Bosiljkov et al. 2005b; Tomazevic 1999; Salmanpour et al. 2015), are compared herein with analytical estimates using Eq. 8. This relationship is based on elastic beam theory, incorporating shear deformation, and may be used to estimate the elastic stiffness of masonry walls in single-curvature, such as those tested herein (Benedetti and Steli 2008; Haach et al. 2010). The elastic stiffness $\mathrm{K}_{\mathrm{el}}$ is a function of the wall thickness (t), length or depth (d) and height (h), as well as the shear and longitudinal elastic moduli, $\mathrm{G}$ and $E$, respectively. The parameter $I=t \times d^{3} / 12$ is the area moment of inertia, $A_{n}=d \times t$ is the plan area of the wall and $\alpha$ depends on the boundary conditions $\left(\alpha_{K}=3.33\right.$ for a cantilever, $\alpha_{K}=0.83$ for fixed-ended conditions). Based on existing data, the ratio between the elastic parameters $\mathrm{G}$ and $\mathrm{E}$ is in the range of 33-40\% (Magenes et al. 2010; Salmanpour et al. 2013). Herein, $\mathrm{G}=0.4 \times \mathrm{E}$ is assumed as suggested by current design guidelines for masonry structures (BSI 2005a).

$$
K_{e l}=\frac{1}{\frac{h^{3}}{\alpha_{K} E I}+\frac{h}{A G}}
$$

The effective stiffness $\mathrm{K}_{\text {eff }}$ typically varies in the range of $40-80 \%$ of the elastic stiffness $\mathrm{K}_{0}$ and may be influenced by the level of axial load and boundary conditions (Bosiljkov et al. 2005b; Salmanpour et al. 2013). For practical applications, $\mathrm{K}_{\mathrm{eff}}$ can be considered as $50 \%$ of the elastic stiffness (Tomazevic 1999). As noted in other studies (Bosiljkov et al. 2005b; Haach et al. 2010), predictions of the elastic stiffness using Eq. (8) often result in unreliable estimates due to the highly anisotropic response of masonry. As shown in Table 6, for the cases considered herein, the effective test stiffness $\mathrm{K}_{\text {eff }}$ is $53-80 \%$ of the initial test stiffness $\mathrm{K}_{0}$, which is within the $40-80 \%$ range noted above. These variations, which occur due to the inherent non-linear behaviour of masonry, would reduce when a lower shear modulus $\mathrm{G} \approx 0.33 \times \mathrm{E}$ is considered (Magenes et al. 2008).

In terms of strength, as noted before, all large walls ultimately failed in diagonal tension. Hence, the following assessments focus only on predicting the shear capacity of shear-controlled walls. Close inspection of the estimated shear capacity for flexure-controlled cases showed that this was generally higher than that obtained from tests, and superior to the shear capacity of shear-controlled walls. In this respect, the current version of Eurocode 8 (BSI 2005b) has two distinct equations which are stipulated for assessing the shear force capacity of unreinforced masonry walls controlled by flexure or governed by shear (Eq. 9a,b).

The shear capacity for shear-governed conditions, denoted here as $\mathrm{V}_{\mathrm{s}}$ and expressed by Eq. 9a, uses the Mohr-Coulomb representation with a corresponding limit imposed on the shear strength indicated in Eq. 9b. The shear capacity for shear-controlled conditions effectively corresponds to the shear-sliding failure mechanism. It is worth pointing out that to assess the shear capacity of shear-dominated members, the in-plane horizontal wall length (i.e. depth d), is reduced to the actual compression zone depth (d'). The reduced depth d' at ultimate for the walls tested in this study was assessed from the full-field DIC measurements. The guidelines available in the new revision of Eurocode 8 (Part 3) (CEN 2018), differentiate between shear sliding $\left(\mathrm{V}_{\mathrm{s}}\right)$ and diagonal cracking $\left(\mathrm{V}_{\mathrm{d}}\right)$. The shear sliding mechanism has the same formulation as in the current Eurocode 8 (Part 3) (Eq. 9a) (BSI 
2005b), yet the imposed limit on the maximum shear sliding stress is $0.065 \mathrm{f}_{\mathrm{b}}$, as a function of the brick compressive strength $f_{b}$, rather than that for masonry $f_{m}$ (i.e. Equation $9 b$ versus Eq. 9c). Equation (9b) would not apply for historic masonry with compressive strength below 2.0 MPa.

$$
\begin{gathered}
V_{s}=\left(f_{v 0}+0.4 \frac{N}{d^{\prime} t}\right) d^{\prime} t \leq V_{s, \lim } \\
V_{s, \lim }=0.065 f_{m} d^{\prime} t \\
V_{s, \mathrm{lim}}=0.065 f_{b} d^{\prime} t
\end{gathered}
$$

Equation (10), which can be used to estimate the diagonal cracking failure capacity, is similar to Eq. 5 which is employed to describe the second regime of the shear-compression diagram, with due account for the masonry wall length $d$, thickness $t$, and a correction factor $\mathrm{b}$. The latter accounts for the shear stress distribution in the panel and its aspect ratio $(1.0 \leq b=h / d \leq 1.5$, in which $h$ and $d$ are the height and depth of the panel, respectively).

The diagonal cracking failure mechanism of irregular masonry walls is related to the diagonal tensile strength $f_{t}$, which is obtained from diagonal compression tests such as those described in Sects. 2.2 and 3.1 using Eq. (11) (CEN 2018). The formulation to assess the shear strength of regular masonry walls controlled by diagonal cracking in Eq. 12a, related to the formation of stair-stepped cracks, also reverts back to the shear sliding case, bounded by a limit $\mathrm{V}_{\mathrm{d}, \mathrm{lim}}($ Eq. 12b).

The parameters $\mathrm{f}_{\mathrm{v} 0}$ ' and $\mu$ ' are equivalent shear sliding parameters which relate the shear strength of the panel to the local mechanical properties of the mortar joint, similarly to Eqs. 5d,e described in Sect. 4.1 (Mann and Müller 1982). The interlocking coefficient $\varphi$ is defined as the ratio between the height of the brick unit and the length of overlapping between units. The brick tensile strength $\mathrm{f}_{\mathrm{bt}}$ can be obtained from tests or typically assumed as $10 \%$ of the compressive strength $\mathrm{f}_{\mathrm{b}}$ (CEN 2018). In the assessments undertaken in this paper, the shear sliding parameters were determined based on previous test data (Bompa and Elghazouli 2020a), and by using the ranges illustrated in Fig. 13 and described before. The parameter d' in Eq. 12a corresponds to the depth of the compressed area at the end section of the pier, whilst the vertical stress $\sigma$ calculated for the compressed part of the wall $\left(d^{\prime} \times t\right)$. The stress $\sigma_{0}$ in Eqs. (10 and $\left.12 b\right)$ is the mean vertical stress in the transverse section of the panel, equal to the ratio between the axial force at the centre of the panel $\mathrm{N}$ and the full cross-sectional area $(d \times t)(C E N ~ 2018)$. This corresponds to the applied vertical stress in the tests as indicated in Table 4.

This provides a more realistic representation of the key failure modes for masonry, as also noted in Sect. 4.1 and illustrated in Fig. 13.

$$
\begin{gathered}
V_{d}=\frac{t \cdot d}{b} f_{t} \sqrt{1+\frac{\sigma_{0}}{f_{t}}} \\
f_{t}=\frac{P}{(d+h) t} \\
V_{d}=\frac{t \cdot d^{\prime}}{b}\left(f_{v 0}^{\prime}+\mu^{\prime} \sigma\right) \leq V_{d, \lim }
\end{gathered}
$$


where $f_{v 0}^{\prime}=\frac{f_{v 0}}{1+\mu_{j} \varphi}$ and $\mu^{\prime}=\frac{\mu_{j}}{1+\mu_{j} \varphi}$

$$
V_{d, \lim }=\frac{t \cdot d}{b} \frac{f_{b t}}{2.3} \sqrt{1+\frac{\sigma_{0}}{f_{b t}}}
$$

Table 8 depicts the test shear capacity $\mathrm{V}_{\text {test }}$ of the large walls as well as estimates of Eqs. (9-12). It can be observed that the governing assessment case would always be the shear sliding, irrespective of whether this is obtained from Eq. 9a or the limit in Eq. 9c. This failure mode was not observed in any of the tests. From a direct comparison between the tests and the estimated shear sliding capacity, the predictions are found to be conservative with $\mathrm{V}_{\text {test }} / \mathrm{V}_{\mathrm{s}}=1.18$. Moreover, the estimated flexural strengths are within similar ranges with test strengths, with $\mathrm{V}_{\text {test }} / \mathrm{V}_{\mathrm{f}}=1.03$ and a coefficient of variation of 0.11 . Finally, the estimated $V_{d}$ values are found to be closest to $V_{\text {test }}$, when the test material parameters are used. The average $\mathrm{V}_{\text {test }} / \mathrm{V}_{\mathrm{d}}$ ratio is 1.02 with a coefficient of variation of 0.04 . As the latter condition has the lowest variance and the average closest to unity, it is suggested that Eqs. 12a,b can be used reliably for assessing the diagonal tension capacity of masonry with constituents similar to those described in Sect. 2.1. Based on the above observations and direct correlation with the failure modes occurring in the specimens, available codified expressions can be generally used to provide a reliable estimate of the diagonal tension capacity.

\subsection{Idealised lateral load-deformation curves}

The lateral load-deformation (P- $\Delta$ ) response of a masonry wall can be represented by an idealised piecewise linear relationship with due account for progressive strength degradation (CEN 2018). With reference to Fig. 14, the characteristic points of the relationship can be represented by a bi-linear elastic representation before yield in which the first stage up to $70 \%$ of the peak strength $\left(\mathrm{V}_{\mathrm{u}}\right)$ is a function of the elastic stiffness $\mathrm{K}_{\mathrm{el}}$, and the second stage up to $\mathrm{V}_{\mathrm{u}}$ is based on $25-50 \%$ reduction in $\mathrm{K}_{\mathrm{el}}$. In the inelastic regime, a constant slope is assumed between the yield drift $\Delta_{\mathrm{y}}$ and ultimate drift $\Delta_{\mathrm{u}}$. The latter corresponds to a drop in the shear force with respect to the peak value, to a 'second' ultimate drift $\Delta_{\mathrm{u} 2}$, by an amount that depends on the failure mechanism (i.e. flexure, sliding, diagonal tension). Regardless of the failure mode, the 'second' ultimate drift $\Delta_{\mathrm{u} 2}$ is assumed as $4 / 3$ of

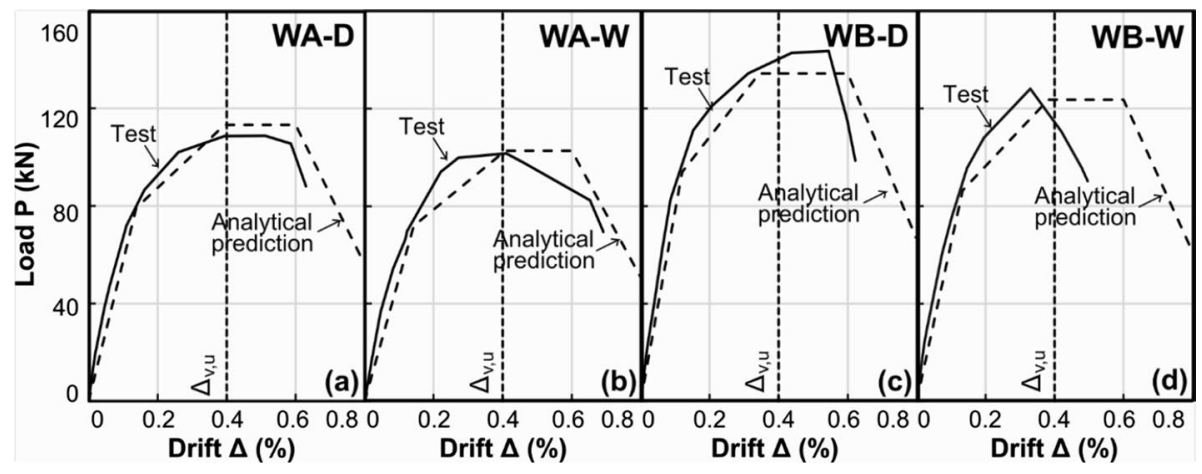

Fig. 14 Comparative V- $\Delta$ curves for Specimens: a WA-D, b WA-W, c WB-D, d WB-W 
the ultimate drift $\Delta_{\mathrm{u}}$ (i.e. $\Delta_{\mathrm{u} 2}=1.33 \times \Delta_{\mathrm{u}}$ ) (BSI 2005b; CEN 2018). The limits $\Delta_{\mathrm{u}}$ and $\Delta_{\mathrm{u} 2}$ are considered to correspond to the Significant Damage and Near Collapse limit states, respectively.

According to current seismic assessment guidelines (BSI 2005b), for shear-governed cases, the drift capacity is limited to $\Delta_{\mathrm{v}, \mathrm{u}}=0.40 \%$. The revised draft of Eurocode 8 (Part 3) (CEN 2018) offers a similar but more detailed procedure to determine the in-plane deformation response of unreinforced masonry walls. For shear sliding failures of historic (premodern) masonry, a value of $\Delta_{\mathrm{s}, \mathrm{u}}=0.8 \%$ is stipulated, while when shear sliding is limited by masonry unit strength $\left(\mathrm{V}_{\mathrm{s}, \mathrm{units}}\right), \Delta_{\mathrm{s}, \mathrm{u}}=0.5 \%$ is suggested, with $\Delta_{\mathrm{s}, \mathrm{u} 2}=1.33 \times \Delta_{\mathrm{s}, \mathrm{u}}$. The residual shear strength corresponding to $\Delta_{\mathrm{s}, \mathrm{u} 2}$ is that estimated from Eq. (9) without considering the contribution of the initial shear strength $\left(\mathrm{f}_{\mathrm{v} 0}\right)$. Conversely, if shear sliding is governed by $\mathrm{V}_{\mathrm{s} \text {,units}}$, the residual shear strength is half the sliding strength without the contribution of $\mathrm{f}_{\mathrm{v} 0}$. Similarly, for diagonal failures of walls, the ultimate drift is considered as $\Delta_{\mathrm{d}, \mathrm{u}}=0.6 \%$ for regular (stair-stepped joints) and as $\Delta_{\mathrm{d}, \mathrm{u}}=0.5 \%$ for irregular masonry, again with $\Delta_{\mathrm{d}, \mathrm{u} 2}=1.33 \times \Delta_{\mathrm{d}, \mathrm{u}}$. The residual shear force corresponding to $\Delta_{\mathrm{d}, \mathrm{u} 2}$ is $50 \%$ of the shear resistance for regular masonry and $30 \%$ for irregular masonry.

The above drift limits suggested by the revised draft of Eurocode 8 (CEN 2018), along with the predictions of Eqs. (9-12) are used herein to construct the load versus drift response of the large-scale wall specimens. The elastic stiffness $\mathrm{K}_{\mathrm{el}}$ was estimated using Eq. (8) and a 50\% reduction in $\mathrm{K}_{\mathrm{el}}$ was considered for the second pre-yield regime $\left(\Delta<\Delta_{\mathrm{y}}\right)$. Figure 14 illustrates a comparative assessment between the test response $\left(\mathrm{V}_{\text {test }}-\Delta_{\text {test }}\right)$ and the estimated diagonal tension $\left(\mathrm{V}_{\mathrm{d}}-\Delta_{\mathrm{d}}\right)$ response. The drift limits for shear $\Delta_{\mathrm{v}, \mathrm{u}}$ that conform to the current version of Eurocode 8 (BSI 2005b) are also indicated by vertical lines in the figure. These are shown to be generally conservative for conventional dry walls through the obtained test-to-estimated drift ratios, noting that similar performance levels have been observed in shear-dominated tests available in the literature (Salmanpour et al. 2013; Frumento et al. 2009).

As shown in Fig. 14a-d, the estimated $\mathrm{V}_{\mathrm{d}}-\Delta_{\mathrm{d}}$ relationships corresponding to diagonal tension failure agree well with the $\mathrm{V}_{\text {test }}-\Delta_{\text {test }}$ curves of the dry specimens WA-D and WB-D, in terms of stiffness, limit of elasticity, peak strength as well as ultimate drifts. In contrast, the $\mathrm{V}_{\text {test }}-\Delta_{\text {test }}$ curves of the wet members (WA-W and WB-W) tend to exhibit a higher degradation in the post-peak regime. This is shown by a more pronounced drop in strength as well as a more inclined descending slope. By direct comparison between the test and predicted V- $\Delta$ curves, it is concluded that if the material properties are determined with due account for the strength reduction due to moisture, then Eq. (12) in conjunction with drift parameters in the first two paragraphs of this section can offer a similar level of reliability for the assessment of both wet and dry masonry walls. Although improved predictions can be obtained through existing detailed analytical procedures (Wilding and Beyer 2017; Salmanpour et al. 2015), the simplified V- $\Delta$ curves discussed above can generally provide a largely conservative prediction of the behaviour.

\section{Conclusions}

This paper presented an experimental investigation into the structural response of ambientdry and wet clay-brick/lime-mortar masonry elements representative of those in some historic structures. A detailed account of tests on large-scale walls subjected to gravity load 
and lateral displacements was given. In addition, complementary tests on square panels under diagonal compression, and cylindrical cores in compression, was also described. Although, as expected, there is significant inherent variability in the properties of masonry elements, depending on the constituent materials and construction conditions, this investigation offered a detailed insight into the influence of moisture on the behaviour, with emphasis on the response of large-scale walls subjected to lateral cyclic displacements and co-existing pre-compression. In addition to providing information for the validation of detailed nonlinear cyclic numerical simulations, the results enabled the assessment of the material shear-compression strength envelopes as well as the key structural performance parameters of wet and dry masonry walls under lateral loading conditions. The adequacy of available design models in terms of stiffness, strength and load-deformation response was also examined. The main concluding remarks are presented below.

The extent of moisture effects is a function of the loading conditions and governing behaviour, as a result of several factors including the relative influence on the mechanical and interaction characteristics of brick and mortar as well as their relative geometry. A direct comparison between the load displacement curves of dry and wet masonry specimens tested under diagonal compression showed that moisture reduced both the elastic stiffness and the strength by up to $39 \%$ and $43 \%$, respectively, compared to the dry counterparts. Full-field DIC measurements also showed that the cracking load was reduced by moisture with the brick-to-mortar interface bond loss occurring at around $75 \%$ and $85 \%$ of ultimate for the wet and dry specimens, respectively. On the other hand, compression tests on cylindrical masonry cores indicated that all uniaxial compression properties were lower when moisture was present. For the configurations tested in this study, the reduction in the elastic modulus and compressive strength obtained from cylindrical cores was up to $23 \%$ and $20 \%$, respectively, between the dry and wet cases. This was compared to about $50 \%$ reduction in strength due to moisture effects for mortar-only specimens, noting that the strength of brick-only specimens are largely unaffected by moisture.

For the large-scale masonry walls tested under cyclic lateral loading and typical levels of gravity load, reductions of up to $20 \%$ in stiffness and up to $11 \%$ in lateral strength were observed in the presence of moisture. All specimens tested under cyclic loading had a brittle failure in diagonal tension with stepped cracks occurring at the two wall diagonals. The ultimate deformations of the wet cyclic walls were either broadly similar or lower than that of the dry counterparts. Considering the ratio of ultimate-to-yield deformation obtained from a bilinear representation as a measure of ductility, the wet walls had ductility drift ratios of up to $12 \%$ lower than those of their dry counterparts.

The tests on small scale specimens were used to assess the shear-compression failure envelopes. It was shown that for the configurations assessed in this paper, the envelopes for wet masonry lie consistently within those for dry masonry, indicating reductions in strength across all shear-compression ranges as a function of the governing response. Finally, analytical assessments related to the performance of large-scale walls indicated that typical estimates for the elastic stiffness were about two-third of the initial stiffness obtained in the tests, in agreement with other results from the literature. Importantly, although codified guidance may not be able to predict the failure mode obtained in tests in a realistic manner, their predicted shear capacity of diagonal tension-governed elements were found to be largely reliable. Overall, it was shown that, provided the material properties are determined with due account for the expected strength reduction due to moisture, existing analytical expressions offer a broadly similar level of adequacy for predicting the response of both dry and wet masonry walls. 
Acknowledgements This study was carried out within the project "Interdisciplinary approach for the management and conservation of UNESCO World Heritage Site of Historic Cairo-Application to Al-Ashraf Street" supported by Newton-Mosharafa funding program, a joint fund by the Science, Technology and Innovation Funding Authority (STIFA) of Egypt, Grant No. AHRC30799 and the Arts and Humanities Research Council (AHRC) of the UK, Grant No. AH/R00787X/1. The authors would also like to acknowledge the support provided by the technical staff of the Structures Laboratories at Imperial College London, particularly Mr. P. Crudge, Mr. L. Clark, and Mr. T. Stickland.

Data availability Selected data for this study is accessible upon written request.

\section{Declarations}

Conflict of interest There are no conflicts of interest for this paper.

Open Access This article is licensed under a Creative Commons Attribution 4.0 International License, which permits use, sharing, adaptation, distribution and reproduction in any medium or format, as long as you give appropriate credit to the original author(s) and the source, provide a link to the Creative Commons licence, and indicate if changes were made. The images or other third party material in this article are included in the article's Creative Commons licence, unless indicated otherwise in a credit line to the material. If material is not included in the article's Creative Commons licence and your intended use is not permitted by statutory regulation or exceeds the permitted use, you will need to obtain permission directly from the copyright holder. To view a copy of this licence, visit http://creativecommons.org/licenses/by/4.0/.

\section{References}

Almeida JA, Pereira EB, Barros JA (2015) Assessment of overlay masonry strengthening system under inplane monotonic and cyclic loading using the diagonal tensile test. Constr Build Mater 94:851-865

Amade AM, Martin JV, Colville J (2004) The effect of moisture on compressive strength and modulus of brick masonry. In Proc. 13th International Brick and Block Masonry Conference. Amsterdam. PMid (Vol. 15043442).

Secil Argamassas, Natural hydraulic lime (NHL) - the binder. Available at: https://www.secilargamassas.pt/ uploads/documentos/Ficha_Tecnica_NHL_5.pdf [accessed 10 November 2019]

Asteris PG, Chronopoulos MP, Chrysostomou CZ, Varum H, Plevris V, Kyriakides N, Silva V (2014) Seismic vulnerability assessment of historical masonry structural systems. Eng Struct 62:118-134. https:// doi.org/10.1016/j.engstruct.2014.01.031

ASTM (2002) ASTM E519-02 - Standard test method for diagonal tension (Shear) in Masonry Assemblages, ASTM

Benedetti A, Steli E (2008) Analytical models for shear-displacement curves of unreinforced and FRP reinforced masonry panels. Constr Build Mater 22(3):175-185. https://doi.org/10.1016/j.conbuildmat. 2006.09.005

Beyer K (2012) Peak and residual strengths of brick masonry spandrels. Eng Struct 41:533-547

Beyer K, Dazio A, Priestley N (2011) Shear deformations of slender reinforced concrete walls under seismic loading. ACI Struct J 108:167-177

Bompa DV, Elghazouli AY (2020a) Experimental and numerical assessment of the shear behaviour of lime mortar clay brick masonry triplets. Constr Build Mater 262:120571. https://doi.org/10.1016/j.conbu ildmat.2020.120571

Bompa DV, Elghazouli AY (2020b) Compressive behaviour of fired-clay brick and lime mortar masonry components in dry and wet conditions. Mater Struct 53:60. https://doi.org/10.1617/ s11527-020-01493-w

Bompa DV, Elghazouli AY (2021) Mechanical properties of hydraulic lime mortars and fired clay bricks subjected to dry-wet cycles. Report. Imperial College London.

Borri A, Castori G, Corradi M (2011) Shear behavior of masonry panels strengthened by high strength steel cords. Constr Build Mater 25(2):494-503. https://doi.org/10.1016/j.conbuildmat.2010.05.014

Bosiljkov VZ, Totoev YZ, Nichols JM (2005) Shear modulus and stiffness of brickwork masonry: an experimental perspective. Struct Eng Mech 20(1):21-43. https://doi.org/10.12989/sem.2005.20.1.021 
Bosiljkov VZ, Totoev YZ, Nichols JM (2005a) Shear modulus and stiffness of brickwork masonry: an experimental perspective. Struct Eng Mech 20(1):21-44

BSI (1999a) BS EN 1015-1 Methods of test for masonry Part 1: determination of compressive strength. British Standards Institution: UK

BSI (1999b) BS EN 1015-2: Methods of test for mortar for masonry-Part 2: Bulk sampling of mortars and preparation of test mortars. British Standards Institution, UK

BSI (1999c) BS EN 1015-3:1999 Methods of test for mortar for masonry — Part 3: Determination of consistence of fresh mortar (by flow table). British Standards Institution, UK

BSI (2004) BS EN 1998-1: Eurocode 8: Design of structures for earthquake resistance. Part 1: General rules, seismic actions and rules for buildings

BSI (2005a) BS EN 1996-1-1 Eurocode 6: Design of masonry structures-General rules for reinforced and unreinforced masonry structures. British Standards Institution, UK

BSI (2005b) BS EN 1998-3: Eurocode 8. Design of structures for earthquake resistance. Assessment and retrofitting of buildings. British Standards Institution

BSI (2010) BS EN 459-2. Building lime: test methods. British Standards Institution, UK

BSI (2011) BS EN 771-1:2011+A1:2015. Specification for masonry units Part 1: Clay masonry units. British Standards Institution, UK

BSI (2012) BS EN 933-1:2012. Tests for geometrical properties of aggregates Part 1: Determination of particle size distribution-Sieving method. British Standards Institution, UK

BSI (2013) BS EN 13139 Aggregates for mortar. British Standards Institution, UK.

BSI (2019) BS EN 1015-11 Methods of test for mortar for masonry — Part 11: Determination of flexural and compressive strength of hardened mortar. British Standards Institution, UK

Calderini C, Cattari S, Lagomarsino S (2010) The use of the diagonal compression test to identify the shear mechanical parameters of masonry. Constr Build Mater 24(5):677-685. https://doi.org/10.1016/j. conbuildmat.2009.11.001

Calvi GM, Kingsley GR, Magenes G (1996) Testing of masonry structures for seismic assessment. Earthq Spectra 12(1):145-162. https://doi.org/10.1193/1.1585872

Capozucca R (2011) Experimental analysis of historic masonry walls reinforced by CFRP under in-plane cyclic loading. Compos Struct 94(1):277-289. https://doi.org/10.1016/j.compstruct.2011.06.007

CEN (2018) CEN/TC250/SC8, 2018. Eurocode 8: Design of structures for earthquake resistance - Part 3: Assessment and retrofitting of buildings and bridges. Final Document EN1998-3 NEN SC8 PT3. Working draft 2018-05-22. European Committee for Standardization

Corinaldesi V (2012) Environmentally-friendly bedding mortars for repair of historical buildings. Constr Build Mater 35:778-784. https://doi.org/10.1016/j.conbuildmat.2012.04.131

Costigan A, Pavía S, Kinnane O (2015) An experimental evaluation of prediction models for the mechanical behavior of unreinforced, lime-mortar masonry under compression. J Build Eng 4:283-294

DeJong M, Penna A (2016) Design of masonry structures. In: Seismic design of buildings to eurocode 8. CRC, pp 249-268

Dorji J, Zahra T, Thambiratnam D, Lee D (2021) Strength assessment of old masonry arch bridges through moderate destructive testing methods. Construct Build Mater 278:122391

Drougkas A, Roca P, Molins C (2016) Compressive strength and elasticity of pure lime mortar masonry. Mater Struct 49(3):983-999. https://doi.org/10.1617/s11527-015-0553-2

El-Attar AG, Saleh AM, Zaghw AH (2005) Conservation of a slender historical Mamluk-style minaret by passive control techniques. Struct Control Health Monit 12(2):157-177

ElGawady MA, Lestuzzi P, Badoux M (2005) In-plane seismic response of URM walls upgraded with FRP. J Compos Constr 9(6):524-535. https://doi.org/10.1061/(ASCE)1090-0268(2005)9:6(524)

Elghazouli A (ed) (2016) Seismic design of buildings to Eurocode 8. CRC Press, Cambridge

Elghazouli A., Butler A., Mourad S., Cheeseman C., Elyamani A, 2018, Interdisciplinary approach for the management and conservation of UNESCO World Heritage Site of Historic Cairo. Application to Al-Ashraf Street. UK Research and Innovation, viewed 7 July 2019, https://gtr.ukri.org/projects?ref= AH\%2FR00787X\%2F1

Flores V, Sanchez-Tizapa S, Arroyo R, Barragan R (2013) Mechanical properties of solid clay brick masonry used in Chilpancingo, Gro (Mexico). Informes De La Construccion 65(531):387-395. https:// doi.org/10.3989/ic.12.084

Franzoni E, Gentilini C, Graziani G, Bandini S (2014a) Towards the assessment of the shear behaviour of masonry in on-site conditions: a study on dry and salt/water conditioned brick masonry triplets. Constr Build Mater 65:405-416. https://doi.org/10.1016/j.conbuildmat.2014.05.002

Franzoni E, Pigino B, Leemann A, Lura P (2014b) Use of TEOS for fired-clay bricks consolidation. Mater Struct 47(7):1175-1184. https://doi.org/10.1617/s11527-013-0120-7 
Frumento S, Magenes G, Morandi P, Calvi GM (2009) Interpretation of experimental shear tests on clay brick masonry walls and evaluation of q-factors for seismic design. IUSS Press, Pavia

Gentilini C, Franzoni E, Bandini S, Nobile L (2012) Effect of salt crystallisation on the shear behaviour of masonry walls: an experimental study. Constr Build Mater 37:181-189. https://doi.org/10.1016/j. conbuildmat.2012.07.086

Ghiassi B, Vermelfoort AT, Lourenço PB (2019) Masonry mechanical properties. In Numerical modeling of masonry and historical structures (pp. 239-261). Woodhead Publishing.

Giaccone D, Santamaria U, Corradi M (2020) An experimental study on the effect of water on historic brickwork masonry. Heritage 3(1):29-46. https://doi.org/10.3390/heritage3010003

Giaretton M, Dizhur D, Garbin E, Ingham JM, da Porto F (2018) In-plane strengthening of clay brick and block masonry walls using textile-reinforced mortar. J Compos Constr 22(5):04018028. https://doi.org/ 10.1061/(ASCE)CC.1943-5614.0000866

Haach VG, Vasconcelos G, Lourenço PB (2010) Experimental analysis of reinforced concrete block masonry walls subjected to in-plane cyclic loading. J Struct Eng 136(4):452-462. https://doi.org/10. 1061/(ASCE)ST.1943-541X.0000125

Hendry AW (1990) Structural masonry. Macmillan International Higher Education. Macmillan Press Ltd

Hendry AW (1997) Shear strength criteria and related tests for brick masonry. Adv Struct Eng 1(2):135-141

Hoła A, Matkowski Z, Hoła J (2017) Analysis of the moisture content of masonry walls in historical buildings using the basement of a medieval town hall as an example. Procedia Eng 172:363-368. https:// doi.org/10.1016/j.proeng.2017.02.041

Ismail N, Ingham JM (2012) In-situ and laboratory based out-of-plane testing of unreinforced clay brick masonry walls strengthened using near surface mounted twisted steel bars. Constr Build Mater 36:119-128. https://doi.org/10.1016/j.conbuildmat.2012.04.087

Ismail N, Petersen RB, Masia MJ, Ingham JM (2011) Diagonal shear behaviour of unreinforced masonry wallettes strengthened using twisted steel bars. Constr Build Mater 25(12):4386-4393. https://doi. org/10.1016/j.conbuildmat.2011.04.063

Koutas L, Bousias SN, Triantafillou TC (2014) Seismic strengthening of masonry-infilled RC frames with TRM: experimental study. J Compos Constr 19(2):04014048. https://doi.org/10.1061/(ASCE) CC.1943-5614.0000507

Kržan M, Gostič S, Cattari S, Bosiljkov V (2015a) Acquiring reference parameters of masonry for the structural performance analysis of historical buildings. Bull Earthq Eng 13(1):203-236

Kržan M, Gostič S, Bosiljkov V (2015b) Application of different in-situ testing techniques and vulnerability assessment of Kolizej palace in Ljubljana. Bull Earthq Eng 13(1):389-410

Li T, Galati N, Tumialan JG, Nanni A (2005) Analysis of unreinforced masonry concrete walls strengthened with glass fiber-reinforced polymer bars. ACI Struct J 102(4):569

Liu K, Wang M, Wang Y (2015) Seismic retrofitting of rural rammed earth buildings using externally bonded fibers. Constr Build Mater 100:91-101. https://doi.org/10.1016/j.conbuildmat.2015.09.048

Lourenço PB, Luso E, Almeida MG (2006) Defects and moisture problems in buildings from historical city centres: a case study in Portugal. Build Environ 41(2):223-234. https://doi.org/10.1016/j.build env.2005.01.001

Lozincă E, Popa V, Coțofană D Cheșcă AB (2016) Unidirectional cyclic behavior of old masonry walls in Romania. In: The 1940 Vrancea earthquake. Issues, insights and lessons learnt. Springer, Cham, pp 351-361. https://doi.org/10.1007/978-3-319-29844-3_24

Magenes G, Calvi GM (1997) In-plane seismic response of brick masonry walls. Earthquake Eng Struct Dynam 26(11):1091-1112

Magenes G, Morandi P, Penna A (2008) D 7.1 c Test results on the behaviour of masonry under static cyclic in plane lateral loads. Test Report, ESECMaSE Poject, University of Pavia, EURCENTRE, Italy.

Magenes G, Galasco A, Penna A, Da Paré M 2010 In-plane cyclic shear tests of undressed double leaf stone masonry panels. In Proceedings of the 14th European conference on earthquake engineering. Ohrid.

Malyszko L (2004) In-plane shear and tensile strength tests of small brickwork specimens. In Structural Analysis of Historical Constructions-2 Volume Set: Possibilities of Numerical and Experimental Techniques-Proceedings of the IVth Int. Seminar on Structural Analysis of Historical Constructions, 10-13 November 2004, Padova, Italy (p. 291). CRC Press.

Mann W, Müller H (1982) Failure of shear-stressed masonry. An enlarged theory, tests and application to shear walls. Proc British Ceramic Soc 30:223-235

Maravelaki-Kalaitzaki P, Bakolas A, Karatasios I, Kilikoglou V (2005) Hydraulic lime mortars for the restoration of historic masonry in Crete. Cem Concr Res 35(8):1577-1586 
Mazzotti C, Sassoni E, Pagliai G (2014) Determination of shear strength of historic masonries by moderately destructive testing of masonry cores. Constr Build Mater 54:421-431. https://doi.org/10. 1016/j.conbuildmat.2013.12.039

Mohamed N, Farghaly AS, Benmokrane B, Neale KW (2014) Flexure and shear deformation of GFRPreinforced shear walls. J Compos Constr 18(2):04013044

Oliveira DV, Lourenço PB, Roca P (2006) Cyclic behaviour of stone and brick masonry under uniaxial compressive loading. Mater Struct 39(2):247-257. https://doi.org/10.1617/s11527-005-9050-3

Pelà L, Kasioumi K, Roca P (2017) Experimental evaluation of the shear strength of aerial lime mortar brickwork by standard tests on triplets and non-standard tests on core samples. Eng Struct 136:441-453. https://doi.org/10.1016/j.engstruct.2017.01.028

Pelà L, Roca P, Aprile A (2018) Combined in-situ and laboratory minor destructive testing of historical mortars. Int J Arch Herit 12(3):334-349

Petry S, Beyer K (2015a) Cyclic test data of six unreinforced masonry walls with different boundary conditions. Earthq Spectra 31(4):2459-2484. https://doi.org/10.1193/101513EQS269

Petry S, Beyer K (2015b) Force-displacement response of in-plane-loaded URM walls with a dominating flexural mode. Earthq Eng Struct Dynam 44(14):2551-2573

Salmanpour AH, Mojsilovic N, Schwartz J (2013) Deformation capacity of unreinforced masonry walls subjected to in-plane loading: a state-of-the-art review. Int J Adv Struct Eng 5(1):22. https://doi. org/10.1186/2008-6695-5-22

Salmanpour AH, Mojsilović N, Schwartz J (2015) Displacement capacity of contemporary unreinforced masonry walls: an experimental study. Eng Struct 89:1-16. https://doi.org/10.1016/j.engstruct. 2015.01.052

Sathiparan N, Rumeshkumar U (2018) Effect of moisture condition on mechanical behavior of low strength brick masonry. J Build Eng 17:23-31. https://doi.org/10.1016/j.jobe.2018.01.015

Sherif AM, Elghazouli AY (2020) Interdisciplinary approach for the management and CONservation of UNESCO World Heritage Site of HIstoric Cairo. Application to Al-Ashraf Street. Second Progress Report Project ID: for STDF: AHRC30799, for AHRC: AH/R00787X/1.

Silva PF, Yu P, Nanni A (2008) Monte Carlo simulation of shear capacity of URM walls retrofitted by polyurea reinforced GFRP grids. J Compos Constr 12(4):405-415

Stafford-Smith B, Carter C, Choudhury JR (1970) The diagonal tensile strength of brickwork. Struct Eng 48(6):219-225

Stephenson V, D’Ayala D (2019) Structural response of masonry infilled timber frames to flood and wind driven rain exposure. J Perform Constr Facil 33(3):04019028

Egernsund Tegl, Chelmer Red Imperial. Available at: https://www.egernsund-tegl.com/products/bricks/2702.2.07-chelmer-red-imperial [accessed 10 November 2019]

Thomas AB 2004 Study of the repair mortars for the Ayyubid City Wall of Cairo. Theses (Historic Preservation), 60. University of Pennsylvania, Philadelphia, PA, United States. Available at: http://repository. upenn.edu/hp_theses/60 (accessed 17/03/2021).

Tomaževič M, Lutman M, Petković L (1996) Seismic behavior of masonry walls: experimental simulation. J Struct Eng 122(9):1040-1047. https://doi.org/10.1061/(ASCE)0733-9445(1996)122:9(1040)

Tomazevic M (1999) Earthquake-resistant design of masonry buildings. Imperial College Press, London, U.K.

Türkmen ÖS, De Vries BT, Wijte SNM, Vermeltfoort AT (2020) In-plane behaviour of clay brick masonry wallettes retrofitted with single-sided fabric-reinforced cementitious matrix and deep mounted carbon fibre strips. Bull Earthq Eng 18(2):725-765

Umair S, Numada M, Amin M, Meguro K (2015) Fiber reinforced polymer and polypropylene composite retrofitting technique for masonry structures. Polymers 7(5):963-984. https://doi.org/10.3390/polym 7050963

Vanin F, Zaganelli D, Penna A, Beyer K (2017) Estimates for the stiffness, strength and drift capacity of stone masonry walls based on 123 quasi-static cyclic tests reported in the literature. Bull Earthq Eng 15(12):5435-5479

Vasconcelos G, Lourenço PB (2009) In-plane experimental behavior of stone masonry walls under cyclic loading. J Struct Eng 135(10):1269-1277. https://doi.org/10.1061/(ASCE)ST.1943-541X.0000053

Wilding BV, Beyer K (2017) Force-displacement response of in-plane loaded unreinforced brick masonry walls: the Critical Diagonal Crack model. Bull Earthq Eng 15(5):2201-2244. https://doi.org/10.1007/ s10518-016-0049-7

Zhou Z, Walker P, D’Ayala D (2008) Strength characteristics of hydraulic lime mortared brickwork. Proc Inst Civ Eng Construct Mater 161(4):139-146. https://doi.org/10.1680/coma.2008.161.4.139 
Publisher's Note Springer Nature remains neutral with regard to jurisdictional claims in published maps and institutional affiliations.

\title{
Authors and Affiliations
}

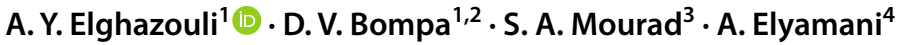 \\ D. V. Bompa \\ d.bompa@surrey.ac.uk \\ S. A. Mourad \\ smourad@eng.cu.edu.eg \\ A. Elyamani \\ a_elyamani@cu.edu.eg \\ 1 Department of Civil and Environmental Engineering, Imperial College London, London, UK \\ 2 Department of Civil and Environmental Engineering, University of Surrey, Guildford, UK \\ 3 Department of Structural Engineering, Cairo University, Giza, Egypt \\ 4 Department of Archaeological Conservation, Cairo University, Giza, Egypt
}

